\title{
Predicting Yield and Stability Analysis of Wheat under Different Crop Management Systems across Agro-Ecosystems in India
}

\author{
Mangi Lal Jat ${ }^{*}$, Raj Kumar Jat ${ }^{3}$, Parvinder Singh ${ }^{1}$, Shankar Lal Jat ${ }^{2}$, Harminder Singh Sidhu, \\ Hanuman Sahay Jat ${ }^{1}$, Deepak Bijarniya ${ }^{1}$, Chiter Mal Parihar ${ }^{2}$, Raj Gupta ${ }^{3}$ \\ ${ }^{1}$ International Maize and Wheat Improvement Center (CIMMYT), National Agriculture Science Center (NASC) Complex, \\ New Delhi, India \\ ${ }^{2}$ Indian Council of Agricultural Research (ICAR), Indian Institute of Maize Research, New Delhi, India \\ ${ }^{3}$ Borlaug Institute for South Asia (BISA), International Maize and Wheat Improvement Center (CIMMYT), New Delhi, India \\ Email: *m.jat@cgiar.org
}

How to cite this paper: Jat, M.L., Jat, R.K., Singh, P., Jat, S.L., Sidhu, H.S., Jat, H.S., Bijarniya, D., Parihar, C.M. and Gupta, R. (2017) Predicting Yield and Stability Analysis of Wheat under Different Crop Management Systems across Agro-Ecosystems in India. American Journal of Plant Sciences, 8, 1977-2012.

https://doi.org/10.4236/ajps.2017.88133

Received: June 19, 2017

Accepted: July 28, 2017

Published: July 31, 2017

Copyright $\odot 2017$ by authors and Scientific Research Publishing Inc. This work is licensed under the Creative Commons Attribution International License (CC BY 4.0).

http://creativecommons.org/licenses/by/4.0/

\begin{abstract}
The objectives of the study were as follows: 1) to evaluate the GxExM for wheat genotypes; 2) to predict yield performance and identify high stable wheat genotypes in different management practices; and 3) to make genotype-specific management and high performing genotype recommendations within and across agro-ecological regions. A diverse set of twenty-one genotypes was evaluated over three years $(2012,2013$ and 2014) under two levels of crop management practices (CT and ZT) across three agro-ecological regions (BR, MP and $\mathrm{PB}$ ) of India in replicated trials. Data were analyzed with SASGxE and RGxE programs using SAS and $\mathrm{R}$ programming languages, respectively. Across and within a location(s), the pattern of GxExM and GxMxY interactions (respectively) among univariate and multivariate stability statistics, grouping of genotypes in divisive clusters and estimates (with a prediction interval) of genotype varied in management practice CT and ZT. Across locations, the genotypes "Munal" and "HD-2967" were the best performers and high stable in CT and ZT, respectively. Genotypes "HD-2824" and "DPW-621-50", and "Munal" may serve as diverse parents for developing high quality, climate smart, locally adapted genotypes for BR in CT and ZT, respectively. Genotypes "HD-2932", "BAZ" and "JW-3288", and "GW-322" and "HD-2967" are suitable for developing locally adapted stress tolerant genotypes for MP in management practices $\mathrm{CT}$ and ZT, respectively. Relatively small GxM and GxExM interactions in $\mathrm{PB}$ preclude in making definitive conclusions.
\end{abstract}

\section{Keywords}

Stability Analysis, GxExM, BLUPs, Forest Plots, GGE Biplot, Wheat, Univariate Stability Statistics 


\section{Introduction}

Worldwide, wheat is the most important staple food as it provides $55 \%$ of the carbohydrates and $20 \%$ of the food calories and protein consumed globally [1]. Demand for wheat is projected to continue to grow over the coming decades, particularly in the developing world to feed an increasing population, and with wheat being a preferred food, continuing to account for a substantial share of human energy needs in 2050 [2]. In India, wheat is the second most important cereal crop after rice. During the past century, India has achieved remarkable progress in increasing wheat production and productivity, primarily due to genetically improved cultivars, expansion of sown areas and better cultural methods. Improved agronomic practices played an important role in enhancing the dependability and sustainability of yields [3] [4]. Yield is a complex quantitative trait and greatly influenced by external environment, which results in scale or rank shift in its performance [5] [6]. This relative shift of genotype performance from one environment (location $\mathrm{x}$ year combination) to another is known as genotype $\mathrm{x}$ environment interaction (GxE) [7] [8]. Substantial studies have been conducted to identify high yielding and consistent performing wheat genotypes (also known as stable genotypes). However, most of the high stable genotypes are less predictable across different crop management practices since plant breeders often perform analysis of two-way data (genotype $\mathrm{x}$ site or GxE) for several consecutive years to detect stable genotypes without taking crop management practices into account. Previous studies on tillage practices, a crop management practice, suggest that optimization of tillage practice alters the dynamic and complex soil in physical, chemical and biological properties [9]-[15]. Proponents of conventional tillage (CT) and zero tillage (ZT) agree on the values of one over the other for crop yield variation across locations and cropping systems [16]-[21]. Understanding interactions among genotype, environment and crop management are important in planning key farm decisions including genotype selection, sustainable farm management and economic planning. In this paper, we propose to identify high yielding and high stable wheat genotypes across environments and over two-crop management practices: CT and ZT.

The impenetrable interaction of a crop bio-system with the soil, the atmosphere, and the environment that a plant lives in introduces challenges when making breeding decisions because it complicates the demonstration of superiority of any genotype across environments. Genotype x environment interaction may result in low correlation between phenotypic and genotypic values, thereby reducing progress from selection. This reduction leads to bias in the estimation of heritability and in the prediction of genetic advance [22] [23] [24]. Several strategies have been proposed to deal with GxE, and the most powerful strategy is to exploit GxE either to develop locally adapted material or to use GxE to better characterize the genotypes [25] [26]. Genotype x environment interaction can be characterized using statistical methods ranging from univariate to multivariate models. The univariate models include regression slope, deviation from regression, environmental variance, and Kang's yield-stability; multi- 
variate models include genotype main effects plus genotype by environment interaction (GGE) biplot, and additive main effects and multiplicative interaction (AMMI) [27]-[33]. Multivariate models could be graphically represented through biplots where genotypes and environments are plotted in a single graph. Recently, hierarchical Bayesian and mixed models were introduced to model heterogeneous variance among environments and different correlation structures among environments [26] [34] [35] [36] [37]. Mixed models allow more flexibility to model unbalanced data using restricted maximum likelihood estimates (REML). Each statistical method reflects different aspects of the GxE, and no single method adequately explains genotype performance across environments [6]. Stability statistics are best used in combination with trait performance (mean or BLUP: Best Linear Unbiased Predictor is an estimate of random effect) and have successfully been used in plant breeding.

In this study, we were interested in understanding differential sensitivity of certain wheat genotypes to different agro-ecological environments in India under different crop management practices for enhancing the selection of superior and stable genotypes. The objectives of the study were as follows: 1) to evaluate the genotype $\mathrm{x}$ environment $\mathrm{x}$ management interaction (GxExM) for wheat genotypes; 2) to predict yield performance and identify high stable wheat genotypes in different management practices; and 3) to make genotype-specific management and high performing genotype recommendations within and across agro-ecological regions.

\section{Materials and Methods}

\subsection{Germplasm, Location and Management}

Twenty-one genotypes of wheat were evaluated across three years (2012, 2103, and 2014) and three locations ranging from western to eastern Indo-Gangetic plains under two different tillage management practices. Locations were chosen to represent the major wheat growing agro-ecological conditions for major wheat production regions in India: Pusa $\left(25^{\circ} 57^{\prime} 08^{\prime \prime N}\right.$; $\left.85^{\circ} 40^{\prime} 13^{\prime \prime} \mathrm{E}\right)$, Bihar (BR), Jabalpur (23 $\left.10^{\prime} 7.6^{\prime \prime N} ; 79^{\circ} 55^{\prime} 55^{\prime \prime E}\right)$, Madhya Pradesh (MP), and Ludhiana $\left(30^{\circ} 59^{\prime} 28^{\prime \prime N} ; 75^{\circ} 44^{\prime} 11^{\prime E}\right.$ ), Punjab (PB) (Supplemental Figure S1 and Supplemental Figure S2). The soils of the experimental plots at three locations, PB, MP and BR, were sandy loam, clay loam and silty loam, respectively. Twenty-one genotypes were semi-dwarf spring wheat chosen to represent new vs. old release; stress resistant vs. susceptible; rust resistant vs. susceptible; eastern vs. northern adapted; tall vs. short stature; early vs. late maturity; low vs. high yield; and varied 1000 kernel weight, protein content, spikelet $e^{-1}$ and seeds spike ${ }^{-1}$. These genotypes are frequently used advanced breeding lines or officially released cultivars. Hereafter the word "genotype" is used to indicate cultigen, cultivar, variety or genotype. Genotypes were considered to be random and representative samples of a wide range of genetic and phenotypic diversity in the wheat germplasm population (Supplemental Table S1). Wheat genotypes were evaluated at two levels of crop management, a conventional tillage (CT) and zero tillage (ZT). 
The CT involved two plowings with disc harrow, the first plowing used a spring-tyne cultivator (about $0.15 \mathrm{~m}$ depth) followed by planking at optimum soil moisture content; and the second plowing involved seeding of different varieties using "Limit-Plot Planter". In ZT, different varieties were directly drilled without any preparatory tillage operations and in the presence of standing stubbles of rice residues $(\sim 15 \mathrm{~cm})$ using "Limit-Plot Planter" with inverted " $\mathrm{T}$ ” tyne openers [38] [39]. A standard seed rate $\left(100 \mathrm{~kg} \cdot \mathrm{ha}^{-1}\right)$, seeding depth $(4 \mathrm{~cm})$, fertilizer nutrient application $\left(120 \mathrm{~kg} \mathrm{~N}, 60 \mathrm{~kg} \mathrm{P}_{2} \mathrm{O}_{5}\right.$ and $\left.60 \mathrm{~kg} \mathrm{~K}_{2} \mathrm{O} \mathrm{ha}{ }^{-1}\right)$, water management (irrigation at standard critical stages) was adopted for both $\mathrm{CT}$ and ZT. These tillage and other management practices correspond to the crop management system commonly used in commercial wheat production in India [40] [41].

\subsection{Trials and Data Description}

At each location, individual trials were established as a two-factor strip-plot (split-block) design with ten genotypes, three replications and two-crop management practices [42]. Out of the ten genotypes, six genotypes were tried at all three locations for three years, and the remaining four genotypes were locationspecific and not necessarily duplicates. These four location-specific genotypes were evaluated at one or two location(s) for either one or all three years. Thus, total distinct genotypes were twenty-one (Supplemental Table S1). Within the blocks, the genotypes were arranged in sub-blocks, and the two-crop managements in the other sub-blocks were arranged perpendicularly to the sub-blocks with the genotypes. The experimental unit (harvest plot) size was $1.6 \mathrm{~m} \times 10 \mathrm{~m}$.

In each location and year, the ten wheat genotypes were evaluated for grain yield $\left(\mathrm{t} \cdot \mathrm{ha}^{-1}\right)$. Wheat grains were harvested using the guide of $15 \%$ moisture in grain, yellowing of spikelets and hard dough stage of grains [11]. Data were missing at random from one replication, one location and one year for genotypes "BAZ", "CSW-16", "CSW16", "CSW-18”, and "DPW-621-50". We excluded three genotypes ("GW-273", "GW-366" and "HD-2687”) that were tested for a time period shorter than three years and only in one location to provide a sufficient representative sample of years and location as random and fixed factors, respectively. As a result of this data preparation, we obtained a four-way genotype $\mathrm{x}$ management $\mathrm{x}$ location $\mathrm{x}$ year interaction $(\mathrm{GxMxLxY})$ dataset for the grain yield of eighteen wheat genotypes (Supplemental Table S1). A set of six genotypes evaluated in all locations were analyzed for across-location statistics. Similarly, a set of ten genotypes (six genotypes from all locations + four unique genotypes from each location) were analyzed for individual location statistics (Supplemental Table S1).

\subsection{Data Analysis and Statistical Methods}

The unbalanced grain yield GxMxLxY data were analyzed for genotype, environment, management, and genotype $\mathrm{x}$ environment $\mathrm{x}$ management interactions with the SASGxE [6] [43] [44] and RGxE [45] [46] programs using SAS and R programming language, respectively, in two steps. During the first stage, we im- 
puted the missing values using the mice() function of the mice (multivariate imputation by chained equations) package [47] of R. Parameters maximum iteration 50 , predictive mean matching ( $\mathrm{pmm}$ ) method and random generator seed value 500 were used in the mice() function to generate five imputed datasets. Then, in the second stage, the five imputed datasets were combined across trials and years to obtain a balanced GxMxLxY mean data for all statistical analyses.

Years and genotypes, and locations and managements were analyzed as random and fixed effects, respectively. Estimates and significance of random effects were computed using RGxE. The random effect model was fit using the lmer() function of lme4 (linear mixed effects models) package [48]. The $F$ ratio (= $\mathrm{MS}_{\text {between }} / \mathrm{MS}_{\text {within, }}$, where MS is mean square or variance estimate) and significance of fixed effects were computed using mixed() function of afex package [49]. The mixed() function computes type III such as $p$-values using the default method via the Kenward-Roger approximation for degrees of freedom. Similarly, the significance of random effects was computed using a likelihood ratio test to attain $p$-values. Likelihood is the probability of the data given a model. The logic of the likelihood ratio test is to compare the likelihood of two models with each other using restricted maximum likelihood (REML) methodology. The model without the factor of interest (the null model) is compared with the model with the factor of interest (the full model) using the anova() function. It gives a ChiSquare value, the associated degrees of freedom and $p$-value. According to Wilk's theorem, the negative two times the log likelihood ratio of two models approaches a Chi-Square distribution with $\mathrm{k}$ degrees of freedom, where $\mathrm{k}$ is number of random effects tested [50].

Univariate stability statistics [regression slope $\left(b_{i}\right)$, deviation from regression $\left(S_{d}^{2}\right)$, Shukla's stability variance $\left(\sigma_{i}^{2}\right)$, and Kang's yield-stability statistics $\left(Y S_{i}\right)$, and BLUP for genotypes were computed using RGxE. Regression slope $\left(b_{i}\right)$ and deviation from regression $\left(S_{d}^{2}\right)$; Shukla's stability variance $\left(\sigma_{i}^{2}\right)$ and Kang's yield-stability statistics $\left(Y S_{i}\right)$; and best linear unbiased predictor (BLUP) for genotypes were computed using $\operatorname{lm}()$ function of $\mathrm{R}$ [51] stability.par() function of the agricolae package [52] and ranef() function of lme4 package [48], respectively. Tests for significance were derived using a t-test for each $b_{i}$ and an $F$ test for each $S_{d}^{2}$ for statistical differences from one and zero, respectively, at 0.05 , 0.01 and 0.001 levels of probability.

SASGxE provided $\mathrm{R}$ code that is ready to use in R statistical software [51] for the analysis of multivariate stability statistics (GGE biplot) [44]. GGE biplot analysis was computed using the "GGEBiplotGUI" package [53], with the support in the helper application "RStudio" [54] in R statistical software. GGE biplot analysis was used to visually assess the presence of genotype $\mathrm{x}$ environment interaction and rank genotype based on stability and mean in each management practice [32] [55]. For each management practice, input data of GGE biplot analysis consisted of genotype $\mathrm{x}$ environment matrix $(2 \times 2)$ of mean values.

Similarly performing genotypes across and within locations and years were clustered using PROC VARCLUS of SAS v9.4 [56]. The VARLCUS procedure used user-defined second eigenvalue cutoff and underlying algorithm called di- 
visive clustering to split a given set of genotypes into two groups. Eigenvalues are the coefficients of principal component analysis. The value 1 of the second eigenvalue is a common choice for cut off because it represents the average size of the eigenvalues. However, we have used the smaller value of the second eigenvalue as 0.7 to account for sampling variability [57]. PROC VARCLUS identified clusters and computed $1-R^{2}$ ratio $\left(\left[1-R_{\text {own cluster }}^{2}\right] /\left[1-R_{\text {next closest }}^{2}\right]\right)$, which identifies a cluster of genotypes that are highly correlated among themselves and not highly correlated with genotypes in other clusters. The graphical representation of divisive clustering, $1-R^{2}$ ratio, forest plot of BLUP along with prediction interval, and the stability statistics summary of each genotype in different management practices across and within locations were computed using SAS PROC TEMPLATE in conjugation with PROC SGRENDER while utilizing the graphical template language (GTL) of SAS v9.4.

\section{Results}

\subsection{Variance Analysis}

The pooled analysis revealed statistically significant fixed effects ( $L, M, M x L)$ for grain yield (Table 1). The variance estimates of the yield for the year (Y) and the

Table 1. Pooled variance analysis for wheat yield $\left(\mathrm{t} \mathrm{ha}^{-1}\right)$ of 6 genotypes tested in 3 years and 3 locations over 2 management practices; and location variance of 10 genotypes tested for 3 years over 2 management practices.

\begin{tabular}{|c|c|c|c|c|c|c|c|c|}
\hline \multirow[b]{3}{*}{ Source } & \multicolumn{2}{|c|}{ Pooled variance $\dagger$} & \multicolumn{6}{|c|}{ Location variance $\neq$} \\
\hline & \multirow[b]{2}{*}{$F$-ratio } & \multirow[b]{2}{*}{$\begin{array}{l}\% \text { of total } \\
\text { variance }\end{array}$} & \multicolumn{2}{|c|}{ Bihar } & \multicolumn{2}{|c|}{ Madhya Pradesh } & \multicolumn{2}{|c|}{ Punjab } \\
\hline & & & $F$-ratio & $\begin{array}{l}\% \text { of total } \\
\text { variance }\end{array}$ & $F$-ratio & $\begin{array}{l}\% \text { of total } \\
\text { variance }\end{array}$ & $F$-ratio & $\begin{array}{l}\% \text { of total } \\
\text { variance }\end{array}$ \\
\hline Year (Y) & & $14.75^{\star * *}$ & & $22.09^{\star *}$ & & $38.88^{\star * *}$ & & $52.54^{* *}$ \\
\hline Location (L) & $1.42^{\star *}$ & & & & & & & \\
\hline $\mathrm{YxL}$ & & $24.37^{\star * *}$ & & & & & & \\
\hline Genotype (G) & & $3.74^{*}$ & & $34.84^{* * *}$ & & $23.63^{* * *}$ & & $12.34^{* *}$ \\
\hline Gx $\mathrm{Y}$ & & $0.17 \mathrm{NS}$ & & $3.48^{\star}$ & & $4.64^{*}$ & & $1.09^{*}$ \\
\hline $\mathrm{G} \times \mathrm{L}$ & & $11.23^{* * *}$ & & & & & & \\
\hline GxYxL & & $3.92^{*}$ & & & & & & \\
\hline Management (M) & $7.16^{*}$ & & $10.73^{\star}$ & & $5.54^{\star}$ & & $0.74^{*}$ & \\
\hline $\mathrm{Mx} \mathrm{Y}$ & & $0.70 \mathrm{NS}$ & & $0.71^{*}$ & & $06.03^{* *}$ & & $01.61^{* *}$ \\
\hline$M \times L$ & $1.03^{*}$ & & & & & & & \\
\hline$M \times L x Y$ & & $10.18^{\star * *}$ & & & & & & \\
\hline $\mathrm{G} \times \mathrm{M}$ & & $9.24^{\star * *}$ & & $26.17^{\star \star \star}$ & & $20.55^{\star *}$ & & $2.55^{\star}$ \\
\hline $\mathrm{G} \times \mathrm{M} \times \mathrm{Y}$ & & $8.74^{* *}$ & & $2.68^{* * *}$ & & $1.27^{\star *}$ & & $0.36^{*}$ \\
\hline$G \times M \times L$ & & $11.72^{\star *}$ & & & & & & \\
\hline$G \times M \times L \times Y$ & & $3.90^{*}$ & & & & & & \\
\hline
\end{tabular}

${ }^{*},{ }^{* *}$, and ${ }^{* * *}=$ significant at $0.05,0.01$, and 0.001 levels of probability, respectively; NS =non-significant. The value of significance presented in " $F$-ratio" column represents $F$ statistics $p$-values for $F$-ratio of fixed effects. Similarly, the value of significance presented in "\% of total variance" column represents $\chi^{2}$ statistics $p$-values of variance estimate of random effects. 'Degrees of freedom: Y-2; L-2, YxL-4; G-5; GxY-10; GxL-10; GxYxL-20; M-1; MxY-2; MxL-2; MxLxY-4; GxM-5; GxMxY-10; GxMxL-10; GxMxLxY-20. 'Degrees of freedom: Y-2; G-9; GxY-18; M-1; MxY-2; GxM-9; GxMxY-18. 9\% total variance is calculated by variance estimate of given factor divided by sum (total) of variance estimate of all the factors. List of factors used in model are presented in source column. 
interaction between year and location $(\mathrm{YxL})$ were different $(p<0.01)$ from zero and accounted for $39 \%$ of the total variation. Except for $\mathrm{GxY}$ and $\mathrm{MxY}$, estimates of the random effects were significant (ranged from $0.17 \%-24 \%$ of the total variance estimate). Large estimate of environment ( $\mathrm{LxY}$ ) variance dominated the expression of genotype effect $(G)$ and interaction between genotype and management (GxM) (Table 1). Within location analysis, both fixed and random effects were significant in BR, MP and PB. In BR and MP, Y, G and GxM caused most of the variation in yield performance of wheat genotype (22\% and $39 \%$, $35 \%$ and $24 \%$, and $26 \%$ and $21 \%$ of the total variance, respectively). In contrast, PB had large Y effect (53\% of total variance), medium G effect (12\% of total variation) and small GxM effect (3\% of total variation) (Table 1).

\subsection{Polygon View of GGE Biplot}

The "polygon" (or which-won-where) view of the GGE biplot is drawn by joining extreme genotypes and perpendicular lines (rays) passing from the polygon sides divides the biplot into sector (Figure 1 and Figure 2). A crossover GxE pattern exists if environments fall into multiple sectors and, thus, different genotypes win for an environment or set of environments in a sector. Conversely, no GxE pattern exists if all environments fall into a single sector and, thus, a single genotype had the highest yield in all environments. In either case, the winning genotype is vertex genotype. If no environment is present in a sector, then vertex genotype of that sector is considered to be a poor performer in all test environments. Genotypes within the polygon were less responsive to location than the vertex genotypes. Across locations, the polygon view of the GGE biplot explained $96 \%$ and $97 \%$ of the genotype and genotype $\mathrm{x}$ environment variation for the management practice CT and ZT, respectively (Figure 1: Panel A and B). For management practice CT, environments were grouped into two sectors with different winning (vertex) genotypes. This confirms the existence of GxE for CT. Conversely, ZT had all the locations grouped into one sector, which suggests that GxE for ZT did not exist. However, the GGL biplots for individual year confirm that the location grouping varied across years for ZT. Results of GGL are presented in Supplemental Figure S3 (Panel B, Panel D and Panel E).

Within location, a polygon view of the GGY biplot explained 96\% and 98\%, $88 \%$ and $84 \%$, and $96 \%$ and $95 \%$ for the management practice CT and ZT, and location BR, MP and PB, respectively (Figure 2: Panel A and Panel B; Panel C and Panel D; Panel E and Panel F). For location BR, environments grouped into two and one sector(s) for management practice CT and ZT, respectively (Figure 2: Panel A and Panel B). This suggests that management practice ZT had single winning genotypes across years, whereas CT had different winning genotypes across years. Location MP had environments grouped into two sectors with different winning (vertex) genotypes in each management practice (Figure 2: Panel C and Panel D). Similarly, for location PB and both management practices, environments were grouped into two sectors with different winning genotypes. However, the pattern of winning genotype and environment grouping are con- 


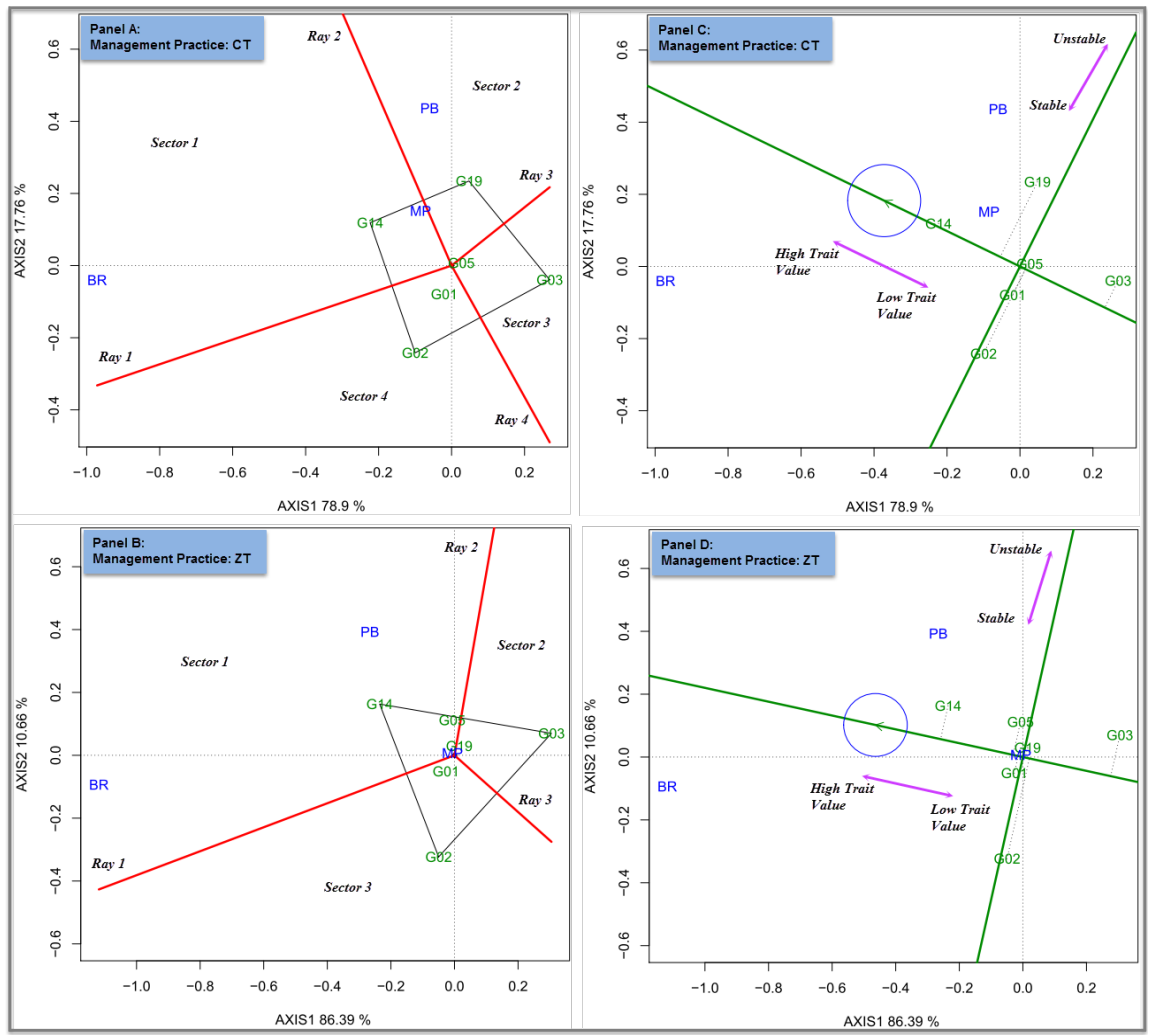

Figure 1. The polygon (which-won-where) (Panel A and Panel B) and mean vs. stability (Panel C and Panel D) view of genotype main effects plus genotype $\mathrm{x}$ environment interaction effect (GGE) biplot of yield of 6 wheat genotypes tested in 3 years, 3 locations over 2 management practices. The biplots were based on Scaling $=0$, Centering $=0$, and $\mathrm{SVP}=2$. Key to the labels of genotype and location is presented in abbreviation section.

sistent in year 2012 (Figure 2: Panel E and Panel F).

\subsection{Genotype BLUPs}

BLUPs are the estimates of random effects. Across locations, estimates of genotype (random effect) for wheat yield ranged from 5.03 to $5.55 \mathrm{t} \cdot \mathrm{ha}^{-1}$ and 5.01 to $5.64 \mathrm{t} \cdot \mathrm{ha}^{-1}$ for management practice CT and ZT, respectively (Table 2). For both management practices (CT and $\mathrm{ZT}$ ), the highest yield was estimated for genotype "HD-2967" and the lowest yield was estimated for genotype "CSW-18". Other high yielding genotypes were "Munal", "BAZ" and "CSW-16".

Within individual location under both management practices, the predicted yield ranged from 4.67 to $5.87 \mathrm{t} \cdot \mathrm{ha}^{-1}$ and 4.64 to $6.09 \mathrm{t} \cdot \mathrm{ha}^{-1}$; 4.84 to $5.17 \mathrm{t} \cdot \mathrm{ha} \mathrm{a}^{-1}$ and 4.77 to $5.14 \mathrm{t} \cdot \mathrm{ha}^{-1}$; and 5.06 to $5.50 \mathrm{t} \cdot \mathrm{ha}^{-1}$ and 5.03 to $5.57 \mathrm{t} \cdot \mathrm{ha}^{-1}$ for location $\mathrm{BR}, \mathrm{MP}$ and $\mathrm{PB}$, and management practice $\mathrm{CT}$ and $\mathrm{ZT}$, respectively (Table 2). Under both management practices, location BR had genotypes "HD-2967" and "CSW-16" with the highest and lowest predicted yield, respectively. For location MP, the highest yield was predicted for genotype "GW-322" and "MPO-1215" in management practice CT and ZT, respectively. Genotypes "JW-3288" and "HD2932" had the lowest predicted yield for management practice CT and ZT, respectively. Location PB had the highest predicted yield for "Munal" and "HD- 


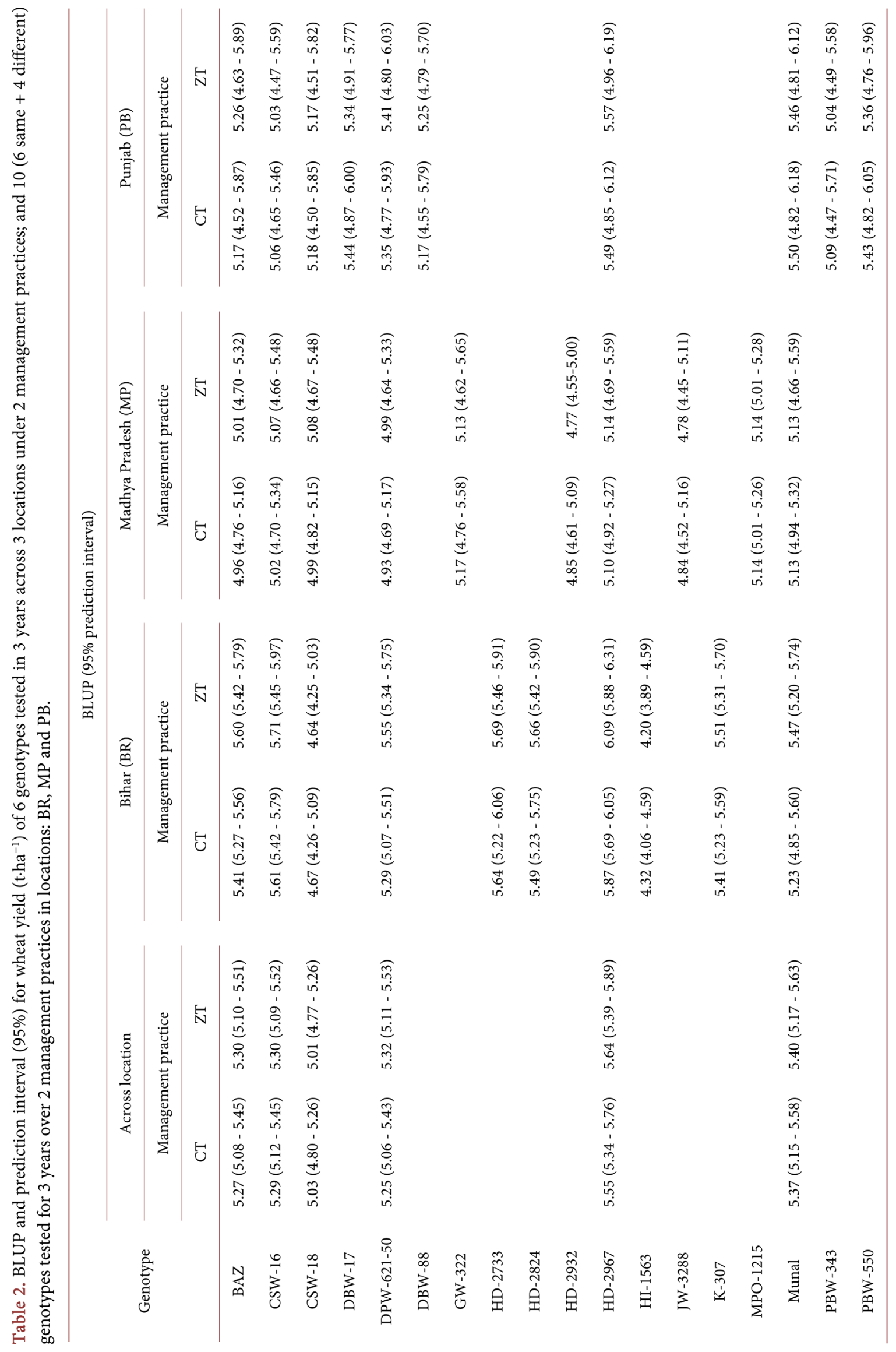




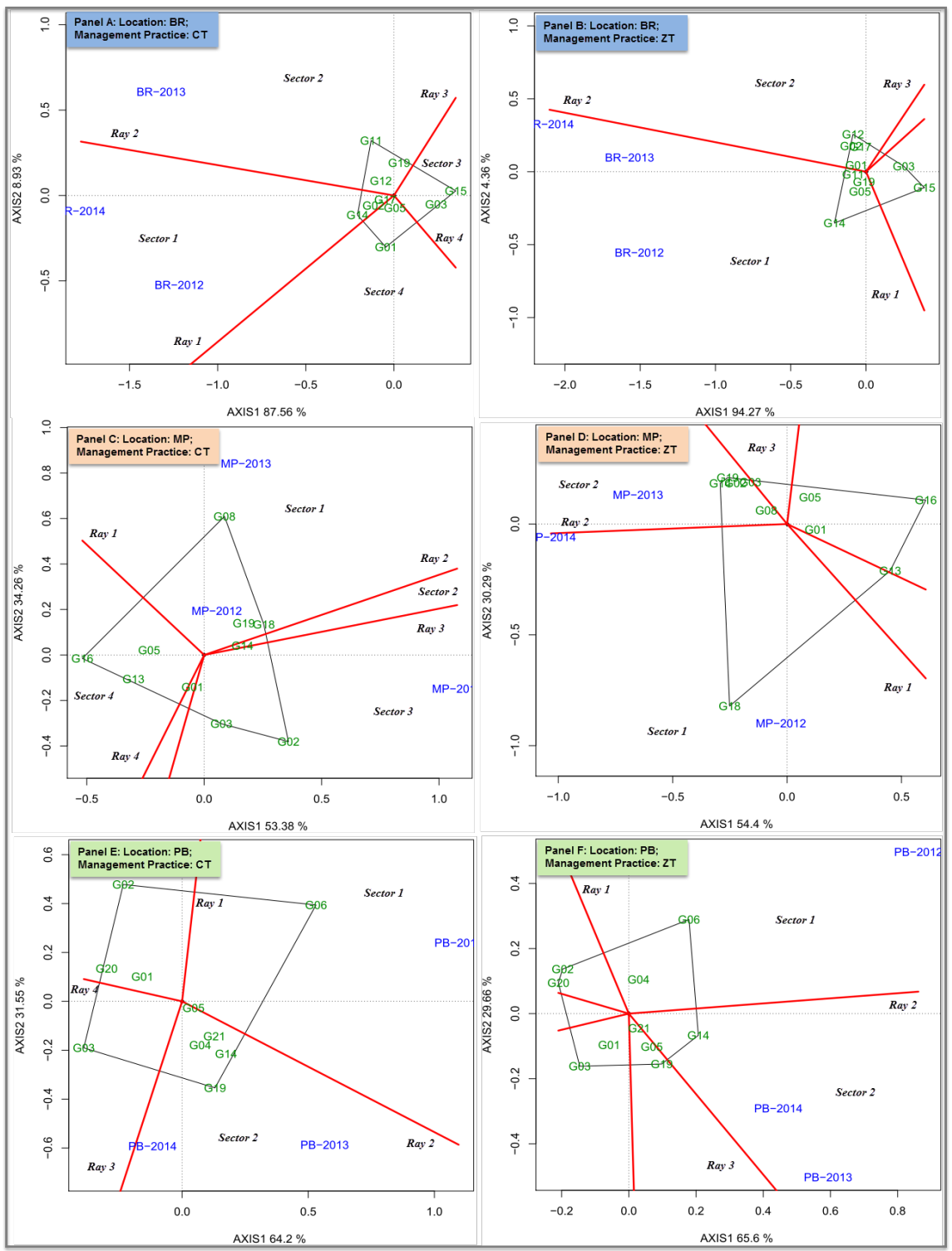

Figure 2. The polygon (which-won-where) view of genotype main effects plus genotype $x$ year interaction effect (GGY) biplot of location BR (Panel A and Panel B), MP (Panel C and Panel D) and PB (Panel E and Panel F) for yield of 10 (6 same +4 different) wheat genotypes tested in 3 years over 2 management practices. The biplots were based on Scaling $=0$, Centering $=0$, and SVP $=2$. Key to the labels of genotype and location is presented in abbreviation section.

2967" in CT and ZT, respectively, and the lowest predicted yield for "CSW-16" in both management practices.

\subsection{Univariate Stability Statistics}

According to Eberhart and Russell (1966), a regression coefficient $\left(b_{i}\right)$ approximating unity, along with deviation from regression $\left(s_{d}^{2}\right)$ near zero, indicates stability. Across locations, the $b_{i}$ value for all six genotypes was close $(p>0.001)$ to unity under both management practices, except for "DPW-621-50" in ZT (Supplemental Table S2). Conversely, the $S_{d}^{2}$ value of all six evaluated geno- 
types was significantly different $(p<0.05)$ from zero, except for "BAZ" in CT. Within individual location under both management practices $b_{i}$ and $S_{d}^{2}$ values were close to unity $(p>0.001)$ and zero $(p>0.001)$, respectively, for all ten tested genotypes. However, the exceptions were "Munal" and "JW-3288" in location MP under management practice CT for $b_{i}$ and $S_{d}^{2}$ values significantly different from one and zero, respectively, and "CSW-16" in location BR under management practice ZT for $S_{d}^{2}$ value significantly different zero. For management practice CT, genotypes "HD-2967"; "HD-2932", "HD-2967" and "JW-3288"; and "DBW-88" had a negative $b_{i}$ value in location BR, MP, and PB, respectively. Similarly, genotype "MPO-1215" had a negative $b_{i}$ value in location MP under management practice ZT.

According to Shukla (1972), a genotype with low $\sigma_{i}^{2}$ is regarded as stable. Across locations, "BAZ" and "DPW-621-50" had significantly low $\sigma_{i}^{2}$ in management practices CT and ZT (Supplemental Table S2). Similarly, under both management practices, genotypes "DPW-621-50"; "BAZ" and "DPW-621-50"; and "DPW-621-50", "HD-2967", "Munal", "PBW-343" and "PBW-550" had low $\sigma_{i}^{2}$ in location $\mathrm{BR}, \mathrm{MP}$, and $\mathrm{PB}$, respectively.

According to $Y S_{i}$ genotypes with $Y S_{i}$ higher than the mean $Y S_{i}$ are stable (represented with symbol " $\sqrt{ }$ " in Supplemental Table S2). Across locations, genotypes "BAZ", "DPW-621-50", "HD-2967" and "Munal" were stable in both management practices. For location $\mathrm{BR}$, stable genotypes in both management practices were "CSW-16", "DPW-621-50", "HD-2733", "HD-2824”, and "HD-2967". Similarly, genotypes “BAZ”, “GW-322”, "HD-2967”, “MPO-1215”, and "Munal” were stable in MP across both management practices. Likewise, in location $\mathrm{PB}$ genotypes “DPW-621-50", “HD-2967”, “Munal”, and "PBW-550” were stable in both management practices.

\subsection{Mean vs. Stability, View of GGE Biplot}

The "average environment coordinate" (AEC) view based on genotype-focused singular value partitioning $(\mathrm{SVP}=1)$ can be referred to as the "mean vs. stability" view [58] of GGE biplot. That view facilitates genotype comparisons based on mean performance and stability across environments within a mega-environment. The "mean vs. stability" view of GGE biplot explained $96 \%$ and $99 \%$ of genotypic and genotype $\mathrm{x}$ environment variation across locations under management practices CT and ZT, respectively (Figure 1: Panel C and D). The arrow shown on the AEC abscissa points in the direction of higher yield performance of genotypes and ranks the genotypes with respect to yield performance. Thus, genotype "HD-2967" (G14) had the highest yield and "CSW-18" (G03) had the lowest under both management practices (Figure 1: Panel C and D). The stability of each genotype was explored by its projection onto the AEC vertical axis. The most stable genotype was located almost on the AEC abscissa (horizontal axis) and had a near-zero projection onto the AEC (vertical axis). Thus, "HD2967" (G14) and "DPW-621-50" (G05), and "Munal" (G19) and "BAZ" (G01) were the most stable in management practices $\mathrm{CT}$ and $\mathrm{ZT}$, respectively (Figure 1: Panel $\mathrm{C}$ and $\mathrm{D}$ ). The ideal genotype has both the high trait mean and stable 
performance [46]. An ideal genotype is represented by a circle on the head of arrow on the AEC abscissa (horizontal axis) (Figure 1: Panel C and D). Across locations, genotype "HD-2967" (G14) was the best in both management practices (Figure 1: Panel C and D). These findings are consistent across years (Supplemental Figure S4).

For location BR, most of the genotypes were clustered near the origin $(0,0)$ of the biplot, which represents the average yield. In CT, "K-307" (G17), "CSW-16" (G02), "HD-2824" (G12) and "HD-2967" (G14) were best. Similarly, in ZT. "BAZ" (G01), "HD-2733” (G11) and "DPW-621-50" (G05) were best (Figure 3: Panel A

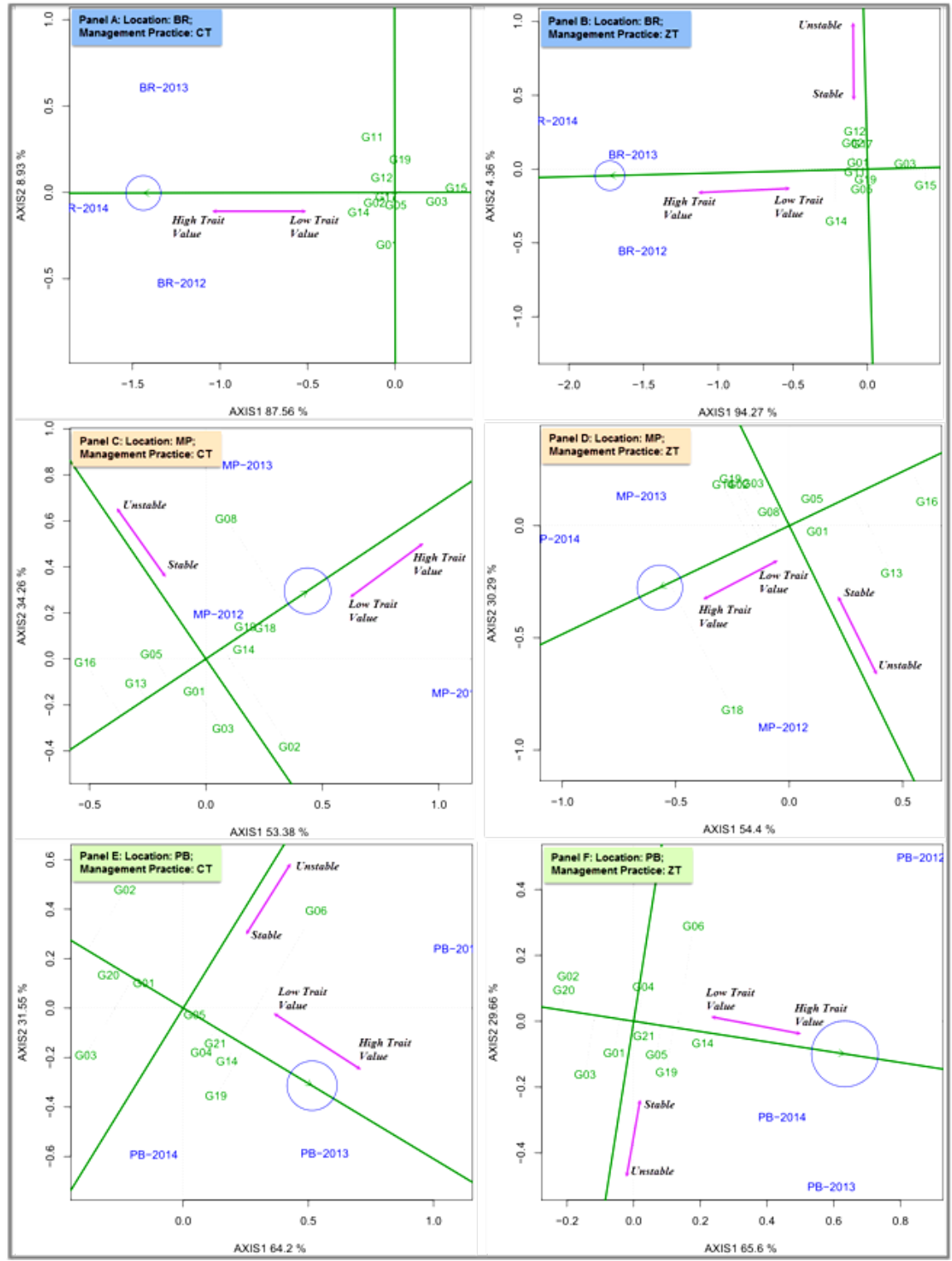

Figure 3. The mean vs. stability view of genotype main effects plus genotype $\mathrm{x}$ year interaction effect (GGY) biplot of location BR (Panel A and Panel B), MP (Panel C and Panel D) and PB (Panel E and Panel F) for yield of 10 (6 same +4 different) wheat genotypes tested in 3 years over 2 management practices. The biplots were based on Scaling $=0$, Centering $=0$, and SVP $=2$. Key to the labels of genotype and location is presented in abbreviation section. 
and Panel B). For location MP, "Munal" (G19) and "MPO-1215" (G18), and "GW-322" (G08) were best in CT and ZT, respectively (Figure 3: Panel C and Panel D). For location PB, "HD-2967" (G14), and "PBW-550" (G21) were best in both management practices (Figure 3: Panel E and Panel F).

\subsection{Divisive Clusters and $1-R^{2}$ ratio}

Across locations under both management practices, similarly performing genotypes were grouped into two clusters (Figure 4: Panel A and Panel B). The most representative and distinct genotype within the cluster has high correlation with its own cluster and low correlation with other clusters [59]. Thus, an ideal representative genotype has a low $1-R^{2}$ ratio $\left(\left[1-R_{\text {own cluster }}^{2}\right] /\left[1-R_{\text {next closest }}^{2}\right]\right)$ value. Across all the tested locations "Munal" and "HD-2967" were the representative genotype of cluster 1 and cluster 2, respectively, in CT (Figure 4: Panel A).

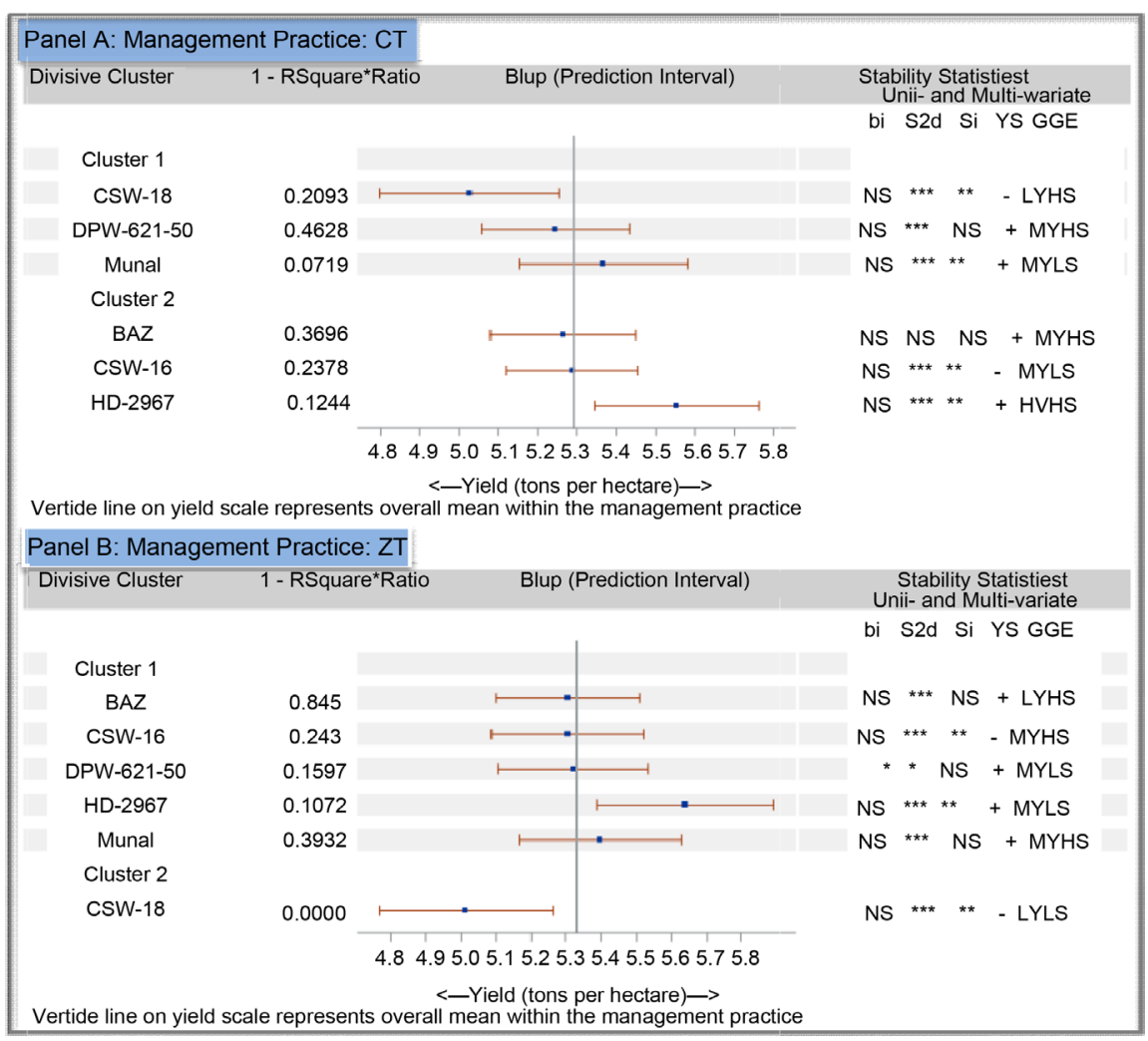

Figure 4. Divisive cluster, $1-\mathrm{R}^{2}$ ratio, forest plot of BLUP along with $95 \%$ prediction interval, and stability statistics summary of yield of 6 wheat genotypes tested in 3 years, 3 locations over 2 management practices. ${ }^{\dagger *},{ }^{*}$ and ${ }^{* *}$ significantly different from unity for the regression coefficients or slope $\left(b_{i}\right)$ and from zero for the deviation from regression $\left(S_{d}^{2}\right)$ and Shukla's stability variance $\left(\sigma_{i}^{2}\right.$ or $\left.S_{i}\right)$ at $0.05,0.01$ and 0.001 levels of probability, respectively. NS is significantly not different. "§» indicates negative slope. “+” and "-" indicate stable and non-stable according to Kang stability statistics $\left(Y S_{i}\right)$, respectively. "HYHS", "HYLS", "MYHS", "MYLS", "LYHS" and "LYLS” indicate "high yield and high stable", "high yield and low stable", "medium yield and high stable", "medium yield and low stable", "low yield and high stable" and "low yield and low stable", respectively. High, medium and low yield is with reference to the center of "mean vs. stability" view of GGE biplot $(0,0)$, which represents the mean yield. 
Similarly, "BAZ" was the representative genotype of cluster 1 in ZT (Figure 4: Panel B). The zero value of $1-R^{2}$ ratio is the result of the presence of a single entity in the cluster and, thus, correlation within its own cluster is 1 $\left([1-1] /\left[1-R_{\text {next closest }}^{2}\right]=0 /\left[1-R_{\text {next closest }}^{2}\right]=0\right)$ (Figure 4: Panel B).

For location $\mathrm{BR}$, similarly performing genotypes across years were grouped into three clusters under both management practices (Figure 5: Panel A and Panel B). In CT, "HD-2824" and "DPW-621-50" were representative genotypes in cluster 1 and cluster 3, respectively (Figure 5: Panel A). In ZT, "Munal", "CSW-16" and "HD-2967" were representative in respective clusters (Figure 5: Panel B). Similarly, for location MP, 5 and 2 clusters were identified in CT and ZT, respectively (Figure 5: Panel C and Panel D). In CT, "HD-2932", "BAZ" and "JW-3288" were representative in cluster 1 , cluster 3 and cluster 4, respectively (Figure 5: Panel C). In ZT, "GW-322" and "Munal" were representative in cluster 1 and cluster 2, respectively (Figure 5: Panel D). For location PB under both management practices, genotypes were grouped into 1 cluster, except for "DBW88 " in CT (Figure 6: Panel A and B).

\section{Discussion}

Across locations, the $F$ ratio of the fixed effects (L, M, MxL) was statistically significant. The mean yield of genotypes for the crop management practices (M), $\mathrm{CT}$ and ZT, was different (results are not presented here) and these results are in agreement with our previous findings [11] [12] [18] [19] [20] [21] [60] [61]. The significant MxL suggests a variable response of genotype yield to the increased intensity of tillage practices across the test locations. Except for $\mathrm{GxY}$ and $\mathrm{MxY}$, estimates of the random effects were significant (Table 1). Similar results were reported in the study by [62] [63] [64] [65] [66]. The estimates of random effects varied from $0.17 \%-24 \%$ of the total variance. The large estimates of $\mathrm{Y}$ and $\mathrm{YxL}$ suggest that the agro-ecological conditions of the test locations were extremely different and accounted for most of the yield variation. Variations in meteorological data across locations confirm the diversity found in agro-ecological conditions of the test locations (Supplemental Figure S1 and Supplemental Figure $\mathrm{S} 2)$. The small contribution of $\mathrm{G}$ in the total variance estimate is due to the fact that genotypes evaluated in this study were advanced breeding lines, elite cultivars or high yielding genotypes. These findings are confirmed with the common parents and number of selfing (inbreeding) found in their pedigree (Supplemental Table S1). The significant variance components for GxM, GxMxL and GxMxLxY led to a different ranking of genotypes across environments under CT and ZT, justifying the development of a stable genotype that performs well over environments in different management practices. The ideal genotype should have a high mean and high stability.

Across locations, the mean predicted (mean of BLUP) yield of ZT is more than CT (represented by the vertical line in Figure 4: Panel A and Panel B). A similar trend of enhanced performance of ZT over CT across nine environments (three locations $\times$ three years) was noticed (Supplemental Figure S5). This 


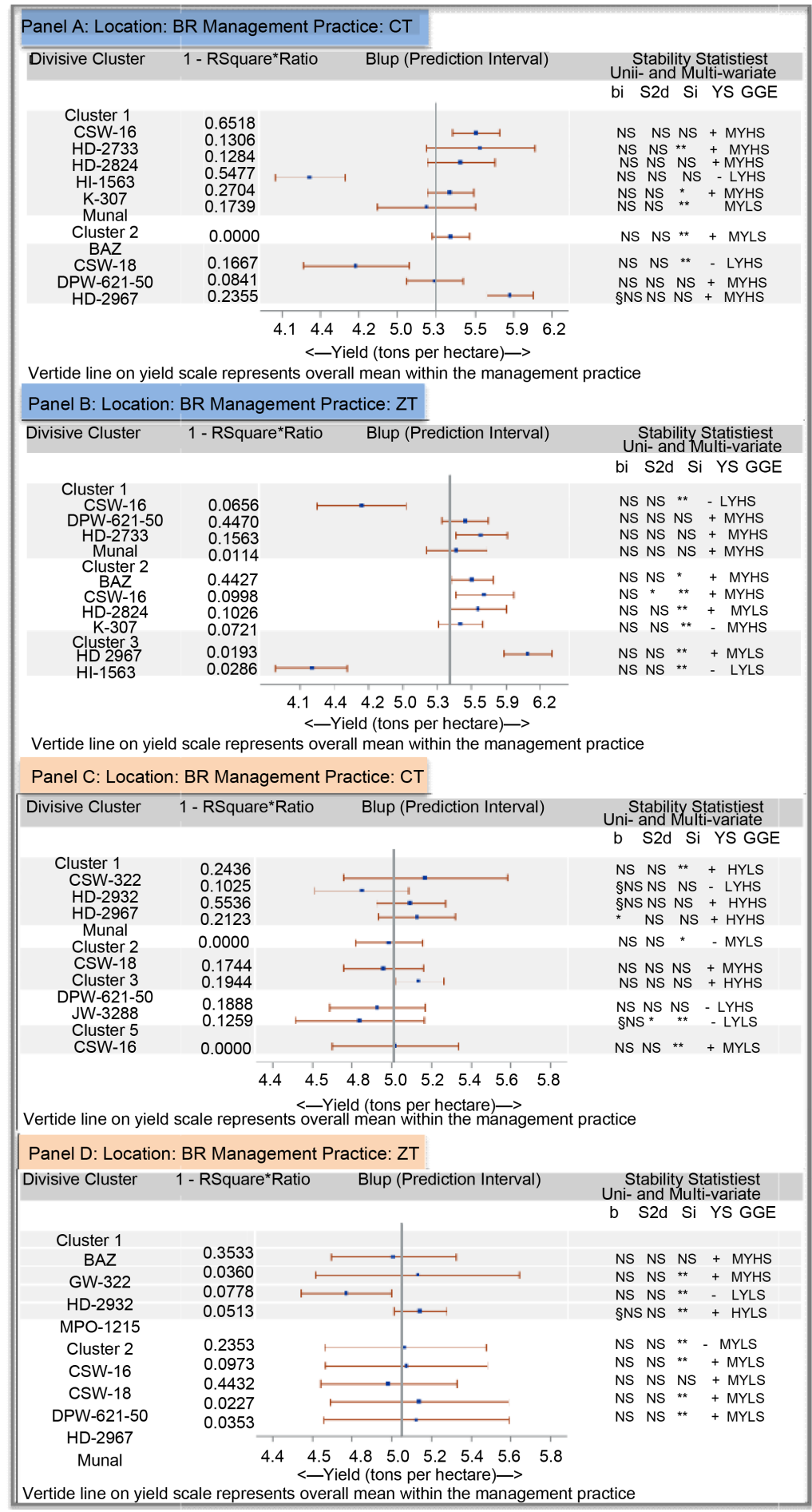

Figure 5. Divisive cluster, $1-\mathrm{R}^{2}$ ratio, forest plot of BLUP along with $95 \%$ prediction interval, and stability statistics summary of locations BR (Panel A and Panel B) and MP (Panel C and Panel D) for yield of 10 (6 same +4 different) wheat genotypes tested for 3 years over 2 management practices. ${ }^{\dagger *},{ }^{* *}$ and ${ }^{* * *}$ significantly different from unity for the regression coefficients or slope $\left(b_{i}\right)$ and from zero for the deviation from regression $\left(S_{d}^{2}\right)$ and Shukla's stability variance $\left(\sigma_{i}^{2}\right.$ or $\left.S i\right)$ at $0.05,0.01$ and 0.001 levels of probability, respectively. NS is significantly not different. "ک” indicates negative slope. “+” and “-” indicate stable and non-stable according to Kang stability statistics $\left(Y S_{i}\right)$, respectively. "HYHS”, "HYLS", "MYHS”, "MYLS", "LYHS” and "LYLS" indicate "high yield and high stable", "high yield and low stable", "medium yield and high stable", "medium yield and low stable", "low yield and high stable" and "low yield and low stable", respectively. High, medium and low yield is with reference to the center of "mean vs. stability" view of GGE biplot $(0,0)$, which represents the mean yield. 


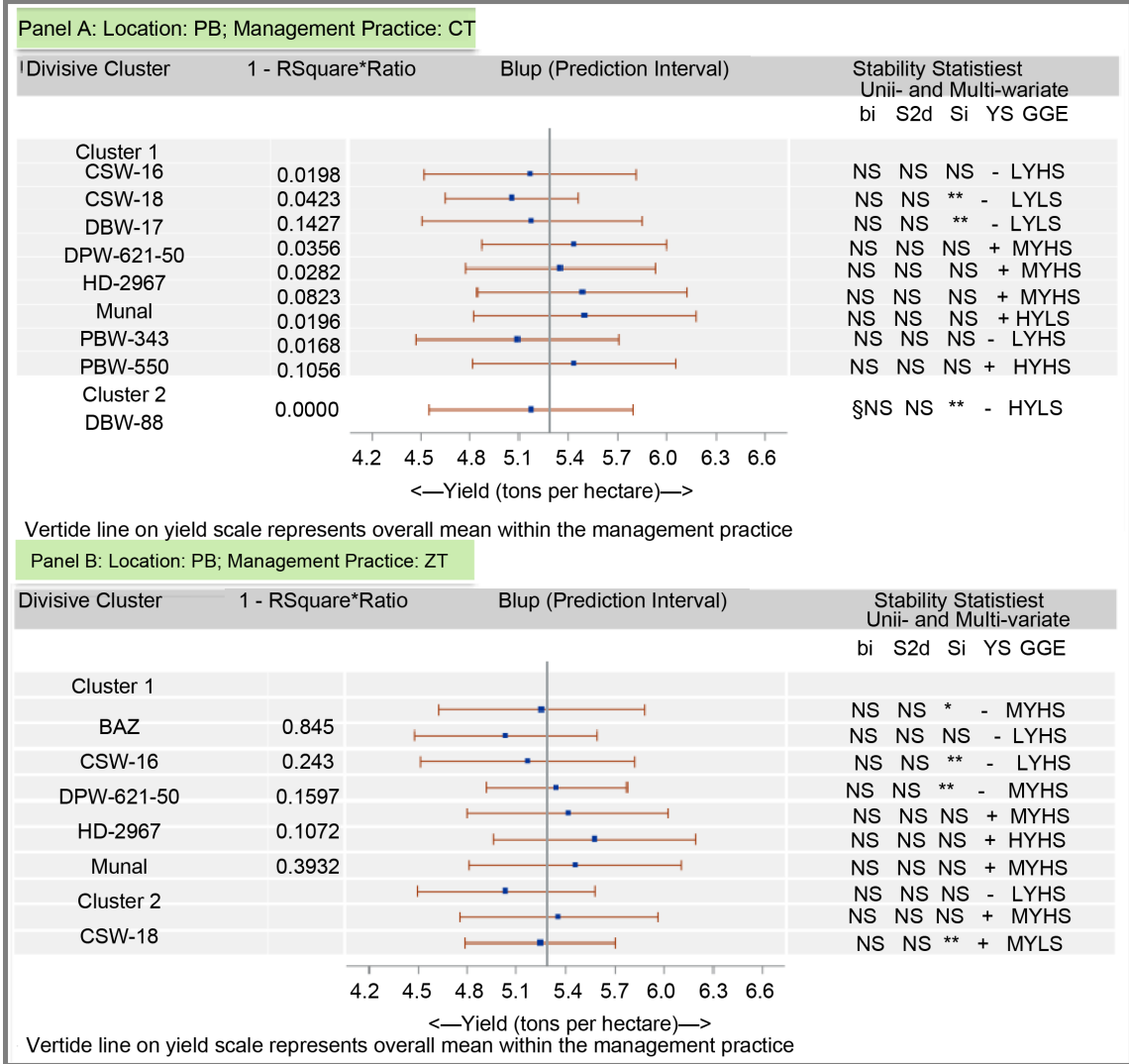

Figure 6. Divisive cluster, $1-\mathrm{R}^{2}$ ratio, forest plot of BLUP along with $95 \%$ prediction interval, and stability statistics summary of locations PB for yield of 10 (6 same +4 different) wheat genotypes tested for 3 years over 2 management practices. ${ }^{\dagger *},{ }^{* *}$ and ${ }^{* * *}$ significantly different from unity for the regression coefficients or slope $\left(b_{i}\right)$ and from zero for the deviation from regression $\left(S_{d}^{2}\right)$ and Shukla's stability variance $\left(\sigma_{i}^{2}\right.$ or $\left.S i\right)$ at $0.05,0.01$ and 0.001 levels of probability, respectively. NS is significantly not different. "§" indicates negative slope. "+" and "-" indicate stable and non-stable according to Kang stability statistics $\left(Y S_{i}\right)$, respectively. "HYHS", "HYLS", "MYHS”, "MYLS", "LYHS" and "LYLS" indicate "high yield and high stable", "high yield and low stable", "medium yield and high stable", "medium yield and low stable", "low yield and high stable" and "low yield and low stable", respectively. High, medium and low yield is with reference to the center of "mean vs. stability" view of GGE biplot $(0,0)$, which represents the mean yield.

could be due to positive effects of ZT on soils specially when the organic matter content of the soils of the study sites is low and is one of the major reasons for deteriorating soil health in this region [67] [68]. In CT, intensive and shallow tillage leads to significant negative impact on soil health and quality parameter, whereas ZT facilitate buildup in soil organic matter, improve soil biological activity and soil structure due to maintenance of soil aggregates, and reduced oxidation of soil organic matter. These findings are in agreement with [69] and [70]. Results of the long-term research by [19] suggests that ZT significantly reduced bulk density and penetration resistance; increased organic carbon, saturated hydraulic conductivity, water stable aggregate, microbial biomass carbon and soil enzyme activities compared to CT. Additionally, ZT facilitates advance planting (ZT drills works well on relatively high soil moisture which is not the 
case for CT), regulates (buffers) soil as well as canopy temperature that helps in developing better root system (mass, density, length) which in turn results into better nutrient uptake and plant withstanding against high velocity winds at grain filling/maturity (reduce lodging) [71].

Based on the mean predictive yield, the six genotypes tested across locations were grouped into high, medium, and low predictive yielders. In both management practices ( $\mathrm{CT}$ and $\mathrm{ZT}$ ), high, medium and low predictive yielding genotypes were "HD-2967" and "Munal"; "BAZ", "CSW-16" and "DPW-621-50"; and "CSW-18", respectively. In CT, high and medium predictive yielding genotypes were grouped into two separate divisive clusters, which confirm the differential performance of genotypes across locations (Figure 4: Panel A). Conversely, in ZT, all high and medium predictive yielding genotypes grouped into 1 cluster (Figure 4: Panel B). The different clustering pattern in CT and ZT suggests the existence of interaction of soil health dynamics due to CT with different genetic composition, plant architecture, and stress tolerant and disease resistance levels of high and medium predictive yielding genotypes (Supplemental Table S1). In ZT, the low predictive yielding genotype "CSW-18" was highly dissimilar among all the tested genotypes and, thus, formed a unique cluster (Figure 4: Panel B). In contrast, the performance profile of "CSW-18" across locations in CT was on par and shared the same cluster (cluster 1) with the medium and high predictive yielding genotypes ("DPW-621-50" and "Munal", respectively) (Figure 4: Panel A). Genotypes grouped into the same cluster with the duplicate $1-\mathrm{R}^{2}$ ratio value provided the same information (redundancy exist) and can be used interchangeably to reduce testing costs and improve efficiency of breeding programs. However, in both CT and ZT, distinct values of $1-\mathrm{R}^{2}$ ratio in each cluster indicated the existence of some extent of dissimilarity among genotypes within the cluster (Figure 4: Panel A and Panel B). This finding can be corroborated with the unique genetic makeup of or distinct parents being used in each genotype (Supplemental Table S1). A definitive conclusion on the most representative and distinct genotype within the cluster must be based on the low value of $1-\mathrm{R}^{2}$ ratio. Thus, "Munal" and "HD-2967" were the most representative and distinct genotype in cluster 1 and cluster 2, respectively, in CT (Figure 4: Panel A). Similarly, "HD-2967" was the most representative and distinct genotype in ZT (Figure 4: Panel A). In CT and ZT, the most representative and distinct genotype(s) had the highest predictive yield (Figure 4: Panel A and Panel B). These findings suggest that genetic composition of "HD-2967" has the ability to outperform regardless of alteration made in soil health due to tillage practice. Therefore, growers must select these high performing genotypes as their preferred varieties according to tillage practice and cropping system is followed in their region. Similarly, wheat breeders can use them as a diverse parent for future breeding purposes while considering tillage practice into account so that actual effect of yield can be exploited.

Based on multiple stability measures, wheat genotypes were classified into three categories. Category 1 genotypes had high predictive yield and high stabil- 
ity, and are widely adopted across varied environmental conditions. These genotypes had $b_{i}$ equal to unity, low or non-nonsignificant $S_{d}^{2}$ and $\sigma_{i}^{2}, Y S_{i}$ higher than mean $Y S_{p}$ and close to ideal genotype and near zero projection onto the AEC (vertical axis) on "mean vs. stability" view of GGE biplot. Genotypes "HD-2967" (G14) and "Munal" (G19) qualified in category 1 for management practices CT and ZT, respectively (Figure 4: Panel A and Panel B). Significant $S_{d}^{2}$ of both genotypes contrasts to the previous study where non-significant $S_{d}^{2}$ was detected for category 1 genotypes [6]. This contrast could be because the errors associated with the slopes of genotypes are not statistically independent [72]. Category 2 genotypes exhibited high predictive yield but low stability. These genotypes had $b_{i}$ greater than unity, high or non-nonsignificant $S_{d}^{2}$ and $\sigma_{i}^{2}$, and high projections onto the AEC (vertical axis) on "mean vs. stability" view of GGE biplot. Thus, these genotypes are suited for specific locations. Results suggest that genotypes "HD-2967" (G14) and "Munal" (G19) were sensitive to environmental change and had greater specificity of adaptability to high yielding environment under management practices $\mathrm{ZT}$ and $\mathrm{CT}$, respectively (Figure 1: Panel C and Panel D). Plant breeders can use these genotypes to develop high performers for specific location and management practices. However, according to $Y S_{i}$, category 2 genotypes were better than average and should be considered as stable. Unlike category 1 genotypes, projection onto AEC on "mean vs. stability" view of GGE biplot, category 2 genotypes had relatively opposite projections. This finding confirms the differential performance of the same genotypes in different management practices. Change of stability (high to low or vice versa) of "HD-2967" (G14) and "Munal" (G19) as tillage practices flipped (CT to ZT or vice versa) suggested that the expression of genes governing yield were dependent on management mediated soil health and related processes. Yield of "HD-2967" (G14) was less influenced when soil had higher bulk density, poor water retention capacity, higher hydraulic conductivity, lower soil organic carbon and lower biological activities (soil properties found under CT, [39]. Thus, growers can use "HD-2967" for consistent performance across locations and in cropping system where CT is practiced. In contrast, "Munal" (G19) is recommended for high yield and high adaptability at specific location where CT is practiced or soil had higher bulk density, poor water retention capacity, higher hydraulic conductivity, lower soil organic carbon and lower biological activities. However, growers have to be careful in using location specific genotypes as they had greater specificity of adaptability to high yielding environments. Meaning small change in favorable environment (CT type soils) will result into large fluctuation in genotype performance. Similarly, genotype "Munal" (G19) and "HD-2967" can be used for consistent performance across and within a specific location(s), respectively, and in cropping system where ZT is practiced. Likewise, breeders have scope to further exploit the genes responsible for differential performance of these high yielding and high stable genotype as soil physical, chemical and biological properties are changed due to optimization of tillage practice. Category 3 genotypes had low to medium predictive yield 
and low stability. These genotypes are suitable for traits (other than yield) such as disease or lodging resistance, where low values are desired in high yielding environments. Category 3 genotypes include "CAW-16" and "CSW-18" in both management practices.

In $\mathrm{BR}$, high predictive yielding genotypes tended to perform better in $\mathrm{ZT}$ over $\mathrm{CT}$, whereas low predictive yielding genotypes performed better in CT. In both $\mathrm{CT}$ and ZT, different genotypes constituted the three clusters, which suggest the differential performance of genotypes across years and management practices within a location. In CT, genotypes "CSW-16", "HD-2824", "K-307", "DPW621-50" and "HD-2967" had high predictive yield and stability across years based on multiple stability measures. These genotypes had greater adaptability in this location under management practice CT. Conversely, genotypes "DPW-62150", "HD-2733", and "Munal" had high predictive yield and stability in ZT. Wheat researchers can use high predictive yielding, high stable and low $1-R^{2}$ ratio genotypes from different clusters as a contrast parent for future breeding purposes. These genotypes include "HD-2824" and "DPW-621-50", and "Munal" in $\mathrm{CT}$ and ZT, respectively.

Similar to BR, in MP, high and low predictive yielding genotypes tended to perform better in ZT and CT, respectively. Relatively, CT resulted in more diverse performances of ten tested genotypes, thus forming 5 clusters. Genotypes "HD-2967", "Munal", "BAZ" and "MPO-1215" had medium to high predictive yield and stable across years in CT. The significant $b_{i}$ value of "Munal" suggested that its performance improved in good years. In ZT, medium predictive yielding genotypes were stable. These genotypes include "BAZ" and "DPW-621-50". High predictive yielding genotypes had large prediction intervals and non-nonsignificant $\sigma_{i}^{2}$. In CT, genotypes "HD-2932", "BAZ" and "JW-3288" with the lowest $1-\mathrm{R}^{2}$ ratio had high stability. In contrast, in $\mathrm{ZT}$, "GW-322" and "HD2967 " had the lowest $1-\mathrm{R}^{2}$ ratio but with low stability. Pedigree of "GW-322" confirmed the presence of stem rust (Sr2, Sr11+), leaf rust ( $\operatorname{Lr} 1, \operatorname{Lr} 10, \operatorname{Lr} 13$, Lr13+), yellow rust (Yr2+) and glutenin (Glu-A1b, Glu-B1b, Glu-D1a) genes (Supplemental Table S1). Glutenin (a type of glutelin) is the major protein of wheat flour. Similarly, "BAZ" and "HD-2932" have adult plant stem rust (Sr2+) and leaf rust ( $L r 13+)$ resistant genes, respectively. Additionally, previous studies have identified that "BAZ" and "GW-322" have capability to withstand heat and drought stress. Therefore, researchers can introgress genes from these genotypes into elite inbreds to make better hybrids with high stability. In $\mathrm{PB}$, a small percentage of the total variation from GxM and GxMxY interactions $(p<0.01)$ suggests that the grain yield variation from these interactions is the least important. Furthermore, estimates of random effects of genotypes revealed mixed response of high and low predictive yielding genotypes in both management practices. Similarly, a divisive cluster did not identify dissimilarity among genotypes, except for genotype "DBW-88" in CT. Likewise, genotypes "DPW-621-50", "HD2967" and "PBW-550" had high predictive yield and high stability in both CT and ZT. The mixed response of high and low predictive yielding genotype could 
be due to dominant nature of complex interaction of low solar radiation and low temperature with pre-anthesis over plant growth-tillage practice interaction. The combined effect of temperature and radiation influence plant process differently. High temperature and low radiation during the phase of rapid spike growth and development (20 - 30 days prior anthesis) result in reduced number of grains $\mathrm{m}^{-2}$ and thousand kernel weight [73]. There is a general consensus among the scientific community that the global temperature is rising due to climate change, and the largest increase in mean temperature is projected for the high latitude regions [74]. PB is relatively situated at higher latitudes and, thus, it might have experienced more temperature fluctuations. Temperature and solar radiation variation among locations tested are confirmed in Supplemental Figure S1.

For the development of stable genotype for grain yield, the pattern of GxExM interaction, grouping of genotypes into divisive clusters and estimates (with prediction intervals) of genotype varied in management practice CT and ZT. Based on the results, it is possible to breed tillage management specific stable genotypes with enhanced stress and quality traits. In dark zones of Indo-Gangetic plains (areas where water table is declining due to overexploitation of ground water resources), the Government of India has been emphasizing on diversification of rice with maize and CT with ZT in rice-wheat cropping system [61] and [19]. Thus, growers can chose tillage practice specific high yielding and high stable genotypes in their cropping system. Across locations, the genotypes "Munal" and "HD-2967" were the best performers and high stable in CT and ZT, respectively. Genotypes "HD-2824" and "DPW-621-50", and "Munal" may serve as diverse parents for developing high quality climate smart, locally adapted genotypes for BR in CT and ZT, respectively. Similarly, genotypes "HD-2932", "BAZ" and "JW-3288", and "GW-322" and "HD-2967" can be used for research purposes for developing locally adapted, stress tolerant genotypes for MP in management practices CT and ZT, respectively.

\section{Supplemental Material Available}

Supplemental material is available with the online version of this article.

\section{Acknowledgements}

This research was funded by Die Bundesministerium für Wirtschaftliche $\mathrm{Zu}$ sammenarbeit und Entwicklung (BMZ/GIZ), Germany. The land and other facilitites for field trials, provided by Borlaug Institute for South Asia (BISA), are thankfully acknowledged. We would like to thank CGIAR Research Program on Wheat Agri-Food Systems (WHEAT) for supporting this study. We express our appreciation to Dr Hans-Joachim Braun, Dr. Ravi P. Singh and Dr. Arun K Joshi of CIMMYT, Mexico, for their support in this research. We would also like to thank Dr. Mahendra Dia from North Carolina State University, NC, USA, for providing his subject matter expertise and support in statistical analysis using SAS and R programming language. 


\section{References}

[1] Mohanty, S.K., Singh, A.K., Jat, S.L., Parihar, C.M., Pooniya, V., Sharma, S., Chaudhary, S., Chaudhary, V. and Singh, B. (2015) Precision Nitrogen-Management Practices Influences Growth and Yield of Wheat (Triticum aestivum) under Conservation Agriculture. Indian Journal of Agronomy, 64, 617-621.

[2] Wageningen, F.S.C. (2016) Multi-Level Mapping and Exploration of Wheat Production and Consumption and Their Potential Contribution to Alleviation of Poverty, Malnutrition and Gender Inequality. Final Report WHEAT Competitive Grant. Wageningen University Food Security Center Study, The Netherlands.

[3] CIMMYT (1996) CIMMYT 1995-96 World Wheat Facts and Trends: Understanding Global Trends in the Use of Wheat Diversity and International Flows of Wheat Genetic Resources. CIMMYT, Mexico.

[4] Singh, V.K., Yadvinder-Singh Dwivedi, B.S., Singh, K.S., Majumdar, K., Jat, M.L., Mishra, R.P. and Rani, M. (2016) Soil Physical Properties, Yield Trends and Economics after Five Years of Conservation Agriculture Based Rice-Maize System in North-Western India. Soil and Tillage Research, 155, 133-148.

https://doi.org/10.1016/j.still.2015.08.001

[5] Dia, M. (2012a) Genotype x Environment Interaction and Stability Analysis of Performance, and Mega-Environment Identification of Fruit Yield and Yield Components in Watermelon [Citrullus lanatus (Thumb.) Matsum \& Nakai] Tested in Multiple US Locations. Ph.D. Thesis, North Carolina State University, Raleigh.

[6] Dia, M., Wehner, T.C., Hassell, R., Price, D.S., Boyhan, G.E., Olson, S., King, S., Davis, A.R. and Tolla, G.E. (2016a) Genotype x Environment Interaction and Stability Analysis for Watermelon Fruit Yield in the US. Crop Science, 56, 1645-1661. https://doi.org/10.2135/cropsci2015.10.0625

[7] Dia, M., Wehner, T.C., Hassell, R., Price, D.S., Boyhan, G.E., Olson, S., King, S., Davis, A.R., Tolla, G.E., Bernier, J., Juarez, B., Sari, N., Solmaz, I. and Aras, V. (2012b) Mega-Environment Identification for Watermelon Yield Testing in the US. Cucurbitaceae. Proceedings of the Xth EUCARPIA Meeting on Genetics and Breeding of Cucurbitaceae, Antalya, 15-18 October 2012, 385-390.

[8] Dia, M., Wehner, T.C., Hassell, R., Price, D.S., Boyhan, G.E., Olson, S., King, S., Davis, A.R., Tolla, G.E., Bernier, J., Juarez, B., Sari, N., Solmaz, I. and Aras, V. (2012c) Stability of Fruit Yield in Watermelon Genotypes Tested in Multiple US Environments. Cucurbitaceae. Proceedings of the Xth EUCARPIA Meeting on Genetics and Breeding of Cucurbitaceae, Antalya, 15-18 October, 2012, 84-88.

[9] Dia, M., Weindorf, D., Thompson, C., Cummings, H., Cacovean, H. and Rusu, T. (2009) Spatial Distribution of Heavy Metals in the Soils of Erath County, Texas. Studia Universitatis Babes-Bolyai, Geographia, 2, 99-114.

[10] Gathala, M.K., Ladha, J.K., Saharawat, Y.S., Kumar, V., Kumar, V. and Sharma, P.K. (2011) Effect of Tillage and Crop Establishment Methods on Physical Properties of a Medium-Textured Soil under a Seven-Year Rice-Wheat Rotation. Soil Science Society of America Journal, 75, 1851-1862. https://doi.org/10.2136/sssaj2010.0362

[11] Jat, M.L., Gathala, M.K., Ladha, J.K., Saharawat, Y.S., Jat, A.S., Vipin, K., Sharma, S.K., Kumar, V. and Raj, G. (2009) Evaluation of Precision Land Leveling and Double Zero-Till Systems in Rice-Wheat Rotation: Water Use, Productivity, Profitability and Soil Physical Properties. Soil and Tillage Research, 105, 112-121. https://doi.org/10.1016/j.still.2009.06.003

[12] Jat, M.L., Gathala, M.K., Saharawat, Y.S., Tetarwal, J.P., Gupta, R. and Singh, Y. (2013) Double No-Till and Permanent Raised Beds in Maize-Wheat Rotation of NorthWestern Indo-Gangetic Plains of India: Effects on Crop Yields, Water Productivity, 
Profitability and soil Physical Properties. Field Crops Research, 149, 291-299. https://doi.org/10.1016/j.fcr.2013.04.024

[13] Sapkota, T.B., Jat, R.K., Singh, R.G., Jat, M.L., Stirling, C.M., Bijarniya, D., Kumar, M., Jat Yadvinder-Singh, M.K., Saharawat, Y.S. and Gupta, R.K. (2017) Soil Organic Carbon Changes after Seven Years of Conservation Agriculture in a Rice-Wheat System of the Eastern Indo-Gangetic Plains. Soil Use and Management, 33, 81-89. https://doi.org/10.1111/sum.12331

[14] Weindorf, D.C., Sarkar, R., Dia, M., Wang, H., Chang, Q., Haggard, B., McWhirt, A. and Wooten, A. (2008a) Correlation of X-Ray Fluorescence Spectrometry and Inductively Coupled Plasma Atomic Emission Spectroscopy for Elemental Determination in Composted Products. Compost Science \& Utilization, 16, 79-82. https://doi.org/10.1080/1065657X.2008.10702361

[15] Weindorf, D., Rinard, B., Zhu, Y., Johnson, S., Haggard, B., McPherson, J., Dia, M., Spinks, C. and McWhirt, A. (2008b) High Resolution Soil Survey of Capulin Volcano National Monument, New Mexico. Soil Horizons, 49, 55-62. https://doi.org/10.2136/sh2008.3.0055

[16] Aryal, J.P., Sapkota, T.B., Stirling, C.M., Jat, M.L., Jat, H.S., Rai, M., Mittal, S. and Sutaliya, J.M. (2016) Conservation Agriculture-Based Wheat Production Better Copes with Extreme Climate Events than Conventional Tillage-Based Systems: A Case of Untimely Excess Rainfall in Haryana, India. Agriculture, Ecosystems and Environment, 233, 325-335. https://doi.org/10.1016/j.agee.2016.09.013

[17] Jat, R.K., Sapkota, T.B., Singh, R.G., Jat, M.L., Kumar, M. and Gupta, R.K. (2014) Seven Years of Conservation Agriculture in a Rice-Wheat Rotation of Eastern Gangetic Plains of South Asia: Yield Trends and Economic Profitability. Field Crops Research, 164, 199-210. https://doi.org/10.1016/j.fcr.2014.04.015

[18] Parihar, C.M., Jat, S.L., Singh, A.K., Kumar, B., Yadvinder-Singh, Pradhan, S., Pooniya, V., Dhauja, A., Chaudhary, V., Jat, M.L., Jat, R.K. and Yadav, O.P. (2016a) Conservation Agriculture in Irrigated Intensive Maize-Based Systems of NorthWestern India: Effects on Crop Yields, Water Productivity and Economic Profitability. Field Crops Research, 193, 104-116. https://doi.org/10.1016/j.fcr.2016.03.013

[19] Parihar, C.M., Yadav, M.R., Jat, S.L., Singh, A.K., Kumar, B., Pradhan, S., Chakraborty, D., Jat, M.L., Jat, R.K., Saharawat, Y.S. and Yadav, O.P. (2016b) Long Term Effect of Conservation Agriculture in Maize Rotations on Total Organic Carbon, Physical and Biological Properties of a Sandy Loam Soil in North-Western IndoGangetic Plains. Soil and Tillage Research, 161, 116-128.

https://doi.org/10.1016/j.still.2016.04.001

[20] Parihar, C.M., Jat, S.L., Singh, A.K., Majumdar, K., Jat, M.L., Saharawat, Y.S., Pradhan, S. and Kuri, B.R. (2017) Bio-Energy, Water-Use Efficiency and Economics of Maize-Wheat-Mungbean System under Precision-Conservation Agriculture in SemiArid Agro-Ecosystem. Energy, 119, 245-256. https://doi.org/10.1016/j.energy.2016.12.068

[21] Yadav, M.R., Parihar, C.M., Jat, S.L., Singh, A.K., Kumar, D., Pooniya, V., Parihar, M.D., Saveipune, D., Parmar, H. and Jat, M.L. (2016) Effect of Long-Term Tillage and Diversified Crop Rotations on Nutrient Uptake, Profitability and Energetics of Maize (Zea Mays) in North-Western India. Indian Journal of Agricultural Sciences, 86, 743-749.

[22] Comstock, R.E. and Moll, R.H. (1963) Genotype-Environment Interactions. In: Hanson, W.D. and Robinson, H.F., Eds., Statistical Genetics and Plant Breeding, NASNRC, Washington DC, 164-196.

[23] Alghamdi, S.S. (2004) Yield Stability of Some Soybean Genotypes across Diverse 
Environment. Pakistan Journal of Biological Sciences, 7, 2109-2114. https://doi.org/10.3923/pjbs.2004.2109.2114

[24] Kumar, R., Dia, M. and Wehner, T.C. (2013) Implications of Mating Behavior in Watermelon Breeding. HortScience, 48, 960-964.

[25] DeLacy, I.H., Basford, K.E., Cooper, M., Bull, J.K. and McLaren, C.G. (1996) Analysis of Multi Environment Trials: An historical Perspective. In: Cooper, M. and Hammer, G.L., Eds., Plant Adaptation and Crop Improvement, Wallingford, UK, CABI, 39-124.

[26] Mathews, K.L., Malosetti, M., Chapman, S., McIntyre, L., Reynolds, M., Shorter, R. and van Eeuwijk, F.A. (2008) Multi-Environment QTL Mixed Models for Drought Stress Adaptation in Wheat. Theoretical and Applied Genetics, 117, 1077-1091. https://doi.org/10.1007/s00122-008-0846-8

[27] Finlay, K.W. and Wilkinson, G.N. (1963) The Analysis of Adaptation in a Plant Breeding Programme. Australian Journal of Agricultural Research, 14, 742-754. https://doi.org/10.1071/AR9630742

[28] Eberhart, S.A. and Russell, W.A. (1966) Stability Parameters for Comparing Varieties. Crop Science, 6, 36-40. https://doi.org/10.2135/cropsci1966.0011183X000600010011x

[29] Shukla, G.K. (1972) Some Statistical Aspects of Partitioning Genotype-Environmental Components of Variability. Heredity, 29, 237-245. https://doi.org/10.1038/hdy.1972.87

[30] Yan, W. (2001) GGEbiplot: A Windows Application for Graphical Analysis of Multi-Environment Trial Data and Other Types of Two-Way Data. Agronomy Journal, 93, 1111-1118. https://doi.org/10.2134/agronj2001.9351111x

[31] Kang, M.S. (1993) Simultaneous Selection for Yield and Stability in Crop Performance Trials: Consequences for Growers. Agronomy Journal, 85, 754-757. https://doi.org/10.2134/agronj1993.00021962008500030042x

[32] Yan, W. and Kang, M.S. (2003) GGE Biplot Analysis: A Graphical Tool for Breeders, Geneticists, and Agronomists. CRC Press, Boca Raton, FL.

[33] Gauch, H.G. (2006) Statistical Analysis of Yield Trials by AMMI and GGE. Crop Science, 46, 1488-1500. https://doi.org/10.2135/cropsci2005.07-0193

[34] Jarquín. D., Pérez-Elizalde, S., Burgueño, J. and Crossa, J. (2016) A Hierarchical Bayesian Estimation Model for Multienvironment Plant Breeding Trials in Successive Years. Crop Science, 56, 2260-2276. https://doi.org/10.2135/cropsci2015.08.0475

[35] Jat, P. and Serre, M.L. (2016) Bayesian Maximum Entropy Space/Time Estimation of Surface Water Chloride in Maryland using River Distances. Environmental Pollution, 219, 1148-1155. https://doi.org/10.1016/j.envpol.2016.09.020

[36] Li, Y., Gibson, J.M., Jat, P., Puggioni, G., Hasan, M., West, J.J., Vizuete, W., Sexton, K. and Serre, M. (2010) Burden of Diseases Attributed to Anthropogenic Air Pollution in the United Arab Emirates: Estimates Based on Observed Air Quality Data. Science of the Total Environment, 408, 5784-5793.

https://doi.org/10.1016/j.scitotenv.2010.08.017

[37] Malosetti, M., Voltas, J., Romagosa, I., Ullrich, S.E. and van Eeuwijk, F.A. (2004) Mixed Models Including Environmental Covariables for Studying QTL by Environment Interaction. Euphytica, 137, 139-145. https://doi.org/10.1023/B:EUPH.0000040511.46388.ef

[38] Kumar, V., Saharawat, Y.S., Gathala, M.K., Jat, A.S., Singh, S.K., Chaudhary, N. and Jat, M.L. (2013) Effect of Different Tillage and Seeding Methods on Energy Use Ef- 
ficiency and Productivity of Wheat in the Indo-Gangetic Plains. Field Crops Research, 142, 1-8. https://doi.org/10.1016/j.fcr.2012.11.013

[39] Singh, V.K., Yadvinder-Singh, Dwivedi, B.S., Singh, S.K., Majumdar, K., Jat, M.L., Mishra, R.P. and Rani, M. (2016) Soil Physical Properties, Yield Trends and Economics after Five Years of Conservation Agriculture Based Rice-Maize System in North-West India. Soil and Tillage Research, 155, 133-148.

https://doi.org/10.1016/j.still.2015.08.001

[40] Choudhary, R., Singh, P., Sidhu, H.S., Nandal, D.P., Jat, H.S., Yadvinder-Singh and Jat, M.L. (2016) Evaluation of Tillage and Crop Establishment Methods Integrated Withrelay Seeding of Wheat and Mungbean for Sustainable Intensification of Cotton-Wheat System in South Asia. Field Crops Research, 199, 31-41. https://doi.org/10.1016/j.fcr.2016.08.011

[41] Jat, H.S., Singh, G., Singh, R., Chaudhary, M., Jat, M.L., Gathala, M.K. and Sharma, D.K. (2015) Management Influences on Maize-Wheat System Performance, Water Productivity and Soil Biology. Soil Use and Management, 31, 534-543.

[42] Mintenko, A.S., Smith, S.R. and Cattani, D.J. (2002) Turfgrass Evaluation of Native Grasses for the Northern Great Plains Region. Crop Science, 42, 2018-2024. https://doi.org/10.2135/cropsci2002.2018

[43] Dia, M., Wehner, T.C., Hassell, R., Price, D.S., Boyhan, G.E., Olson, S., King, S., Davis, A.R. and Tolla, G.E. (2016) Values of Locations for Representing Mega-Environments and for Discriminating Yield of Watermelon in the US. Crop Science, 56, 1726-1735. https://doi.org/10.2135/cropsci2015.11.0698

[44] Dia, M., Wehner, T.C. and Arellano, C. (2016) Analysis of Genotype x Environment Interaction (GxE) Using SAS Programming. Agronomy Journal, 108, 1-15. https://doi.org/10.2134/agronj2016.02.0085

[45] Dia, M., Wehner, T.C. and Arellano, C. (2017) RGxE: An R Program for Genotype x Environment Interaction Analysis. American Journal of Plant Sciences, 8, 16721698. https://doi.org/10.4236/ajps.2017.87116

[46] Dia, M., Wehner, T.C., Perkins-Veazie, P., Hassell, R., Price, D.S., Boyhan, G.E., Olson, S., King, S., Davis, A.R., Tolla, G.E., Bernier, J. and Juarez, B. (2016) Stability of Fruit Quality Traits in Diverse Watermelon Cultivars Tested in Multiple Environments. Horticulture Research, 23, 16066. https://doi.org/10.1038/hortres.2016.66

[47] Buuren, S.V. and Groothuis-Oudshoorn, K. (2011) Mice: Multivariate Imputation by Chained Equations in R. Journal of Statistical Software, 45, 1-67. https://doi.org/10.18637/jss.v045.i03

[48] Bates, D., Maechler, M., Bolker, B. and Walker, S. (2015) Fitting Linear Mixed-Effects Models Using lme4. Journal of Statistical Software, 67, 1-48. https://doi.org/10.18637/jss.v067.i01

[49] Singmann, H., Bolker, B. and Westfall, J. (2015) Afex: Analysis of Factorial Experiments. R Package Version 0.15-2. http://CRAN.R-project.org/package=afex

[50] Winter, B. (2013) Linear Models and Linear Mixed Effects Models in R with Linguistic Applications. http://arxiv.org/pdf/1308.5499.pdf

[51] R Core Team (2016) R: A Language and Environment for Statistical Computing. R Foundation for Statistical Computing, Vienna. http://www.R-project.org/

[52] Mendiburu, F.D. (2015) Agricolae: Statistical Procedures for Agricultural Research. R Package Version 1.2-3. http://CRAN.R-project.org/package=agricolae

[53] Frutos, E., Galindo, M.P. and Leiva, V. (2014) An Interactive Biplot Implementation in R for Modeling Genotype-by-Environment Interaction. Stochastic Environmental Research and Risk Assessment, 28, 1629-1641. 
https://doi.org/10.1007/s00477-013-0821-Z

[54] RStudio Team (2014) RStudio: Integrated Development for R. RStudio, Inc., Boston. http://www.rstudio.com/

[55] Yan, W., Hunt, L.A., Sheng, Q. and Szlavnics, Z. (2000) Cultivar Evaluation and Mega-Environment Investigation Based on GGE Biplot. Crop Science, 40, 597-605. https://doi.org/10.2135/cropsci2000.403597x

[56] SAS Institute (2016) SAS/STAT 9.2 User"s Guide. Second Edition, PROC VARCLUS Statement.

https://support.sas.com/documentation/cdl/en/statug/63033/HTML/default/viewer. $\underline{\text { htm\#statug_varclus_sect004.htm }}$

[57] Jackson, D.A. (1993) Stopping Rules in Principal Components Analysis: A Comparison of Heuristical and Statistical Approaches. Ecology, 74, 2204-2214. https://doi.org/10.2307/1939574

[58] Yan, W., Kang, M.S., Ma, B., Woods, S. and Cornelius, P.L. (2007) GGE Biplot vs. AMMI Analysis of Genotype-by-Environment Data. Crop Science, 47, 643-653. https://doi.org/10.2135/cropsci2006.06.0374

[59] SAS Institute (2017) Predictive Modeling Using Logistic Regression. https://support.sas.com/edu/schedules.html?id=2677\&ctry=US

[60] Saharawat, Y.S., Singh, B., Malik, R.K., Ladha, J.K., Gathala, M., Jat, M.L. and Kumar, V. (2010) Evaluation of Alternative Tillage and Crop Establishment Methods in a Rice-Wheat Rotation in North Western IGP. Field Crops Research, 116, 260267. https://doi.org/10.1016/j.fcr.2010.01.003

[61] Gathala, M.K., Kumar, V., Sharma, P.C., Saharawat, Y.S., Jat, H.S., Singh, M., Kumar, A., Jat, M.L., Humphreys, E., Sharma, D.K., Sharma, S. and Ladha, J.K. (2013) Optimizing Intensive Cereal-Based Cropping Systems Addressing Current and Future Drivers of Agricultural Change in the North-Western Indo-Gangetic Plains of India. Agriculture, Ecosystems and Environment, 177, 85-97. https://doi.org/10.1016/j.agee.2013.06.002

[62] Anderson, W.K., Burgel, A.J., Sharma, D.L., Shackley, B.J., Zaicou-Kunesch, C.M., Miyan, M.S. and Amjad, M. (2011) Assessing Specific Agronomic Responses of Wheat Cultivars in a Winter Rainfall Environment. Crop and Pasture Sciences, 62, 115-124. https://doi.org/10.1071/CP10142

[63] Burgueño, J., Crossa, J., Cotes, J.M., Vicente, F.S. and Das, B. (2011) Prediction Assessment of Linear Mixed Models for Multi Environment Trials. Crop Science, 51, 944-954. https://doi.org/10.2135/cropsci2010.07.0403

[64] De Vita, P., Mastrangelo, A.M., Matteu, L., Mazzucotelli, E., Virzi, N., Palumbo, M., Lo Storto, M., Rizza, F. and Cattivelli, L. (2010) Genetic Improvement Effects on Yield Stability in Durum Wheat Genotypes Grown in Italy. Field Crops Research, 119, 68-77. https://doi.org/10.1016/j.fcr.2010.06.016

[65] Shrestha, S., Asch, F., Dusserre, J., Ramanantsoanirina, A. and Brueck, H. (2012) Climate Effects on Yield Components as Affected by Genotypic Responses to Variable Environmental Conditions in Upland Rice Systems at Different Altitudes. Field Crops Research, 134, 216-228. https://doi.org/10.1016/j.fcr.2012.06.011

[66] Tapley, M., Ortiz, B.V., van Santen, E., Balkcom, K.S., Mask, P. and Weaver, D.B. (2013) Location, Seeding Date, and Variety Interactions on Winter Wheat Yield in Southeastern United States. Agronomy Journal, 105, 509-518. https://doi.org/10.2134/agronj2012.0379

[67] Dwivedi, B.S., Shukla, A.K., Singh, V.K. and Yadav, R.L. (2003) Improving Nitrogen and Phosphorus Use Efficiency through Inclusion of Forage Cowpea in the 
Rice-Wheat System in the Indo-Gangetic Plains of India. Field Crops Research, 84, 399-418. https://doi.org/10.1016/S0378-4290(03)00060-1

[68] Singh, Y., Singh, B. and Timsina, J. (2005) Crop Residue Management for Nutrient Cycling and Improving Soil Productivity in Rice-Based Cropping Systems in the Tropics. Advances in Agronomy, 85, 269-407. https://doi.org/10.1016/S0065-2113(04)85006-5

[69] Beare, M.H., Hendrix, P.F. and Coleman, D.C. (1994) Water-Stable Aggregates and Organic Matter Fractions in Conventional and No-Tillage Soils. Soil Science Society of America Journal, 58, 777-786. https://doi.org/10.2136/sssaj1994.03615995005800030020x

[70] Halvorson, A.D., Brian, J.W. and Alfred, L.B. (2002) Tillage, Nitrogen, and Cropping System Effects on Soil Carbon Sequestration. Soil Science Society of America Journal, 66, 906-912. https://doi.org/10.2136/sssaj2002.9060

[71] Gathala, M.K., Jat, M.L., Saharawat, Y.S., Sharma, S.K. and Ladha, J.K. (2017) Physical and Chemical Properties of a Sandy Loam Soil Under Irrigated Rice-Wheat Sequence in the Indo-Gangetic Plains of South Asia. Journal of Ecosystem \& Ecography, S7, 002.

[72] Kandus, M., Almorza, D., Boggio Ronceros, R. and Salerno, J.C. (2010) Statistical Models for Evaluating the Genotype-Environment Interaction in Maize (Zea mays L.). Phyton (Buenos Ares), 79, 39-46.

[73] Fischer, R.A. (1985) Number of Kernels in Wheat Crops and the Influence of Solar Radiation and Temperature. Journal of Agricultural Science, 105, 447-461. https://doi.org/10.1017/S0021859600056495

[74] Hatfield, J.L., Boote, K.J., Kimball, B.A., Ziska, L., Izaurralde, R.C., Ort, D., Thomson, A.M. and Wolfe, D.A. (2011) Climate Impacts on Agriculture: Implications for Crop Production. Agronomy Journal, 103, 351-370.

https://doi.org/10.2134/agronj2010.0303 


\section{Abbreviations}

AEC $=$ Average environment coordinate

ANOVA = Analysis of variance

$\mathrm{BLUP}=$ Best linear unbiased predictor

$\mathrm{BR}=$ Pusa, Bihar

GGE $=$ Genotype main effects plus genotypic $\times$ environment interaction effect

$\mathrm{GGL}=$ Genotype main effects plus genotypic $\mathrm{x}$ location interaction effect

$\mathrm{GxE}=$ Genotype $\mathrm{x}$ environment interaction

GxMxE or GxMxLxY = Genotype $x$ management $\times$ environment interaction or genotype $\mathrm{x}$ management

$\mathrm{x}$ location $\mathrm{x}$ year interaction

$\mathrm{G}=$ Genotype

G01 or $1=\mathrm{BAZ}$

$\mathrm{G} 02$ or $2=\mathrm{CSW}-16$

$\mathrm{G} 03$ or $3=\mathrm{CSW}-18$

G04 or $4=$ DBW -17

G05 or $5=\mathrm{DBW}-88$

G06 or $6=$ DPW $-621-50$

G07 or $7=\mathrm{GW}-273$

G08 or $8=\mathrm{GW}-366$

G09 or $9=\mathrm{GW}-322$

$\mathrm{G} 10$ or $10=\mathrm{HD}-2824$

G11 or $11=\mathrm{HD}-2687$

G12 or $12=\mathrm{HD}-2733$

G13 or $13=\mathrm{HD}-2932$

G14 or $14=$ HD -2967

G15 or $15=$ HI- 1563

G16 or $16=$ JW 3288

$\mathrm{G} 17$ or $17=\mathrm{K}-307$

G18 or $18=$ MPO-1215

G19 or $19=$ Munal

G20 or $20=$ PBW -343

G21 or $21=$ PBW -550

HYHS $=$ High yield and high stable

HYLS = High yield and low stable

$\mathrm{L}=$ Location

LYHS $=$ Low yield and high stable

LYLS = Low yield and low stable

$\mathrm{M}=$ Management

MET = Multi-environment trial

MP = Jabalpur, Madhya Pradesh

MYHS = Medium yield and high stable

MYLS = Medium yield and low stable

PB = Ludhiana, Punjab 
$\mathrm{PC}=$ Principal component

$\mathrm{RGxE}=\mathrm{R}$ language program for the analysis of genotype stability and location value

REML $=$ Restricted maximum likelihood

SASGxE = SAS program for the analysis of genotype stability and location value SVP $=$ Singular value partitioning $\mathrm{Y}=\mathrm{Year}$

$\sigma_{i}^{2}$ or $S i=$ Shukla's stability variance

$b_{i}=$ Linear regression coefficient

$S_{d}^{2}=$ Deviation from regression

$Y S_{i}=$ Kang's stability statistic 


\section{Supplemental Material Description}

The Supplemental tables provide pedigree, phenotypic and genotypic characteristics, and univariate statistics of tested genotypes for 3 years at 3 locations.

The supplemental figures provide meteorological data of location BR, MP and PB for the year 2012 to 2015, yearly BLUP-genotype main effects plus genotype $\mathrm{x}$ location interaction effect (BLUP-GGL) biplot and mean (95\% CI) for wheat yield $\left(\mathrm{t} \mathrm{ha}^{-1}\right)$ of 6 genotypes tested in 3 years and 3 locations over 2 management practices.

Supplementary Table 1 . The 21 wheat genotypes tested with pedigree, phenotype and genotypic information.

\begin{tabular}{|c|c|c|c|c|c|c|c|c|c|c|}
\hline \multirow[b]{2}{*}{ Genotype\# } & \multirow[b]{2}{*}{$\begin{array}{l}\text { Year of } \\
\text { release }\end{array}$} & \multirow[b]{2}{*}{ Pedigree $^{\S}$} & \multicolumn{7}{|c|}{ Phenotype } & \multirow[b]{2}{*}{ Genotype/genes } \\
\hline & & & Maturity & Height ${ }^{\ddagger \neq}$ & $\begin{array}{c}\mathrm{YP}^{\dagger \dagger} \\
\left(\mathrm{t} \cdot \mathrm{ha}^{-1}\right)\end{array}$ & $\begin{array}{c}\mathrm{TKW}^{\S \S} \\
(\mathrm{g})\end{array}$ & Graing 7 & Type\#\# & $\begin{array}{l}\text { Resistant to } \\
\text { Stem- | Yellow- } \\
\mid \text { Leaf- Rust | } \\
\text { Ug99 + Stress }{ }^{\dagger \dagger}\end{array}$ & \\
\hline G01 BAZ & $\mathrm{UT}^{\dagger}$ & $\begin{array}{c}\text { WAXWING/4/SNI/TR } \\
\text { AP-1/3/KAUZ, } \\
\text { MEX`2/TRAP//KAUZ }\end{array}$ & M & S & 5.50 & 40.2 & WB & B & $\mathrm{Y}|-|-\mid \mathrm{Y}+\mathrm{H}$ & APR (Sr2+) \\
\hline G02 CSW-16 & PPVFRA $^{\ddagger}$ & CL 1449/PBW 343 & $\mathrm{~L}$ & M & 7.00 & 44.0 & BMHL & B & $-|\mathrm{Y}| \mathrm{Y} \mid-+-$ & \\
\hline G03 CSW- $18^{\mathrm{A}}$ & 2016 & PBW 343/CL 1538 & $\mathrm{~L}$ & $\mathrm{~T}$ & 7.00 & 40.0 & $\mathrm{LH}$ & B & $-|Y|-\mid-+-$ & \\
\hline G04 DBW-17 & 2007 & $\begin{array}{c}\text { CMH79A.95/3*CNO79 } \\
\text { //RAJ3777 }\end{array}$ & M & $S$ & 6.30 & 37.0 & $\begin{array}{c}\mathrm{AMBH} \\
\mathrm{L}\end{array}$ & B & $\begin{array}{c}-|\mathrm{Y}| \mathrm{Y} \mid \mathrm{N}+ \\
\mathrm{H}\end{array}$ & $\begin{array}{c}\text { ne1, ne2; Lr23, Lr26+; } \\
\text { Lr46; no-Lr34; Lr1, } \\
\text { no-Lr10, no-Lr19, Lr26, } \\
\text { no-Lr34(MM); Sr2, Sr31+; } \\
\text { Yr9+; marker_Cre3_280, } \\
\text { Cre5; }\end{array}$ \\
\hline $\begin{array}{c}\text { G05 DPW-621-5 } \\
0^{\mathrm{A}}\end{array}$ & 2011 & $\begin{array}{l}\text { KAUZ//ALTAR84/AO } \\
\text { S/3 } \\
\text { /MILAN/KAUZ/4/HUI } \\
\text { TES }\end{array}$ & I & M & 6.98 & 38.0 & - & B & $-|Y| Y \mid-+-$ & \\
\hline G06 DBW-88 ${ }^{\mathrm{P}}$ & 2014 & $\begin{array}{l}\text { KAUZ//ALTAR84/AO } \\
\text { S/3 } \\
\text { /MILAN/KAUZ/4/HUI } \\
\text { TES }\end{array}$ & I & M & 6.99 & 38.0 & $\mathrm{AHM}$ & B & $\begin{array}{c}-|\mathrm{Y}| \mathrm{Y} \mid-+ \\
\mathrm{VD}\end{array}$ & Lr10, Lr13+; Sr11+; \\
\hline G07 GW-273 & 1998 & CPAN 2084/VW 205 & M & M & 5.02 & 42.8 & $\mathrm{AHM}$ & B & $-|-|-\mid N+-$ & $\begin{array}{l}\text { Glu-A1b, Glu-B1i, } \\
\text { Glu-D1d; }\end{array}$ \\
\hline G08 GW-322 ${ }^{\mathrm{M}}$ & 2002 & GW 173/GW 196 & $\mathrm{E}$ & $S$ & 6.63 & 40.3 & ASB & B & $-|-|-\mid N+D$ & $\begin{array}{c}\text { Lr1, Lr10, Lr13; Lr13+; } \\
\text { no-Lr34; Sr2, Sr11+; Yr2+; } \\
\text { Glu-A1b, Glu-B1b, } \\
\text { Glu-D1a; no-1RS; }\end{array}$ \\
\hline G09 GW-366 & 2007 & DL802-3/GW232 & $\mathrm{E}$ & M & 7.79 & 49.0 & WB & B & $\begin{array}{c}\mathrm{Y}|-| \mathrm{Y} \mid \mathrm{N}+ \\
\mathrm{VD}\end{array}$ & \\
\hline G10 HD-2687 ${ }^{\mathrm{Y}}$ & 1999 & CPAN 2009/HD 2329 & M & M & 5.12 & 35.2 & $\mathrm{AHM}$ & B & $-|-|-\mid N+-$ & $\begin{array}{c}\text { ne1, ne2; Lr1, Lr23, Lr26, } \\
\text { LrAPR1; Lr1, Lr23, Lr26; } \\
\text { no-Lr34; Yr9; no-1RS; Lr1, } \\
\text { no-Lr10, no-Lr19, } \\
\text { no-Lr26, no-Lr34(MM); } \\
\text { Glu-A1b , B1d, D1a; }\end{array}$ \\
\hline
\end{tabular}




\section{Continued}

\begin{tabular}{|c|c|c|c|c|c|c|c|c|c|c|c|}
\hline G11 & $\mathrm{HD}-2733^{\mathrm{B}}$ & 2001 & $\begin{array}{l}\text { ATTILA/3/TUI/CARC//C } \\
\text { HEN/ CHTO/4/ ATTILA }\end{array}$ & M & S & 7.15 & 41.0 & AHB & B & $\mathrm{Y}|\mathrm{Y}| \mathrm{Y} \mid \mathrm{N}+\mathrm{L}$ & $\begin{array}{l}\text { Ne1, ne2; Lr26, Lr34; } \\
\text { Lr26; no-Lr34; Lr1, } \\
\text { no-Lr10, no-Lr19, } \\
\text { Lr26, no-Lr34(MM); } \\
\text { Sr31+; Yr9, Yr18; } \\
\text { T1BL.1RS; Glu-A1b, } \\
\text { B1d, D1d; }\end{array}$ \\
\hline G12 & $\mathrm{HD}-2824^{\mathrm{B}}$ & 2004 & $\begin{array}{c}\text { PTO-1/CNO 79/PRL/ } \\
\text { GAA/3/HD } 1951\end{array}$ & M & $S$ & 7.04 & 41.0 & ASB & B & $-|-|-\mid N+L$ & $\begin{array}{l}\text { Lr23, Lr26; no-Lr34; } \\
\text { Lr1, no-Lr10, no-Lr19, } \\
\text { Lr26, no-Lr34(MM); } \\
\text { Sr31; Yr9; T1BL.1RS; }\end{array}$ \\
\hline G13 & HD-2932 ${ }^{\mathrm{M}}$ & 2007 & KAUZ/STAR/HD2643 & - & - & 4.30 & - & - & B & $-|-|-\mid N+-$ & $\begin{array}{c}\text { Lr13+; no-Lr34; } \operatorname{Lr} 1 \\
\text { no-Lr10, no-Lr19, } \\
\text { no-Lr26, } \\
\text { no-Lr34(MM); }\end{array}$ \\
\hline G14 & $\mathrm{HD}-2967^{\mathrm{A}}$ & 2011 & $\begin{array}{c}\mathrm{ALD} / \mathrm{COC} / / \mathrm{URES} / \mathrm{HD} \\
\text { 160M/HD } 2278\end{array}$ & $\mathrm{~L}$ & M & 6.61 & - & $\begin{array}{l}\mathrm{AMBH} \\
\mathrm{L}\end{array}$ & B & $-|Y| Y \mid-+-$ & \\
\hline G15 & HI- $1563^{\text {B }}$ & 2011 & MACS $2496^{*} 2 /$ MC 10 & $\mathrm{E}$ & S & 5.17 & - & - & B & $\mathrm{Y}|\mathrm{Y}| \mathrm{Y} \mid-+-$ & \\
\hline G16 & $J W-3288^{M}$ & 2011 & DOVE/BUC/DL 7882 & M & S & 4.39 & 44.0 & - & B & $Y|-| Y \mid-+-$ & \\
\hline G17 & $\mathrm{K}-307^{\mathrm{B}}$ & 2007 & K 8321/UP 2003 & M & M & 6.51 & 39.1 & - & B & $-|-|-\mid N+-$ & \\
\hline G18 & MPO- $1215^{\mathrm{M}}$ & 2010 & $\begin{array}{c}\text { GW 1113/GW } 1114 / / \mathrm{HI} \\
8381\end{array}$ & $\mathrm{E}$ & $S$ & 6.53 & 51.0 & - & $\mathrm{D}$ & $-|-|-\mid N+-$ & \\
\hline G19 & Munal $^{\mathrm{A}}$ & 2011 & Waxwing ${ }^{\star} 2 /$ Kiritati & $\mathrm{L}$ & $\mathrm{T}$ & 7.00 & 40.2 & - & B & $-|-|-\mid-+L$ & \\
\hline G20 & PBW-343 ${ }^{\mathrm{P}}$ & 1996 & $\begin{array}{l}\text { ND/VG9144//KAL/BB/3/ } \\
\text { YCOS"S"/4/ VEE"5"S" }\end{array}$ & M & M & 6.10 & 41.6 & ASB & B & $\mathrm{N}|\mathrm{N}|-\mid \mathrm{N}+-$ & $\begin{array}{c}\text { ne1, ne2; T1BL.1RS; } \\
\text { Lr26, Sr31, Yr9; Lr26, } \\
\text { Lr34; Lr26; no-Lr34; } \\
\text { Lr1, Lr10, no-Lr19, } \\
\text { Lr26, no-Lr34(MM); } \\
\text { Yr9, Yr18; Yr9, Yr27; } \\
\text { csLV34a, no-Ltn; } \\
\text { vrn1, vrn2, Vrn3; } \\
\text { marker_Cre3_280, } \\
\text { Cre5; Glu-A1a, B1a, } \\
\text { D1d; Glu-A1a, B1c, } \\
\text { D1d; Glu-A3c, B3k/b, } \\
\text { D3b; }\end{array}$ \\
\hline G21 & PBW $-550^{\mathrm{P}}$ & 2008 & $\begin{array}{c}\text { WH } 594 / \text { RAJ } 3858 / / \mathrm{W} \\
485\end{array}$ & M & S & 6.24 & 39.1 & $\begin{array}{l}\mathrm{AMBH} \\
\mathrm{L}\end{array}$ & B & $-|\mathrm{Y}| \mathrm{Y} \mid \mathrm{N}+\mathrm{VD}$ & $\begin{array}{l}\text { ne1, ne2; } \operatorname{Lr} 26, \operatorname{Lr} 34 ; \\
\text { no-Lr34; } \operatorname{Lr} 1, \text { no-Lr10, } \\
\text { no-Lr19, Lr26, } \\
\text { Lr34(MM); }\end{array}$ \\
\hline
\end{tabular}

Source: Wheat Atlas-http://www.wheatatlas.org/ “ “A” = tested in all location for $3 \mathrm{yrs;}$; "B” = tested only in Bihar (BR) for 3 yrs; “M” = tested only in Madhya Pradesh (MP) for 3 yrs; “P” = tested only in Punjab (PB) for 3 yrs; “X” = tested only in MP for 1 yrs; " " $"$ tested only in PB for 1 yrs. "Under participatory trials and demonstration since 2011. "Registered with PPVFRA (Protection of Plant Varieties and Farmers Right Authority, India). ${ }^{\S}$ " $*$ " $=$ backcross, “" $=$ single cross, "//" = double cross. ' Maturity: Early (E), <120 days; medium (M), 120-140 days; late (L), >140 days. " Height: Short (S), <90 cm; medium (M), 90-100 cm; Tall (T), >100 cm. ${ }^{\dagger \dagger}$ Yield potential. ${ }^{\$ S} 1000$ kernel weight. "Grain characteristics: White and bold (WB); bold, medium hard and lustrous (BMHL); long and hard (LH); amber, medium bold, hard and lustrous (AMBHL); amber, hard and medium size (AHM), amber semi-hard and bold (ASB); amber hard and bold (AHB). \#\# Wheat type: Bread wheat (B); Durum wheat (D). ${ }^{i \dagger \dagger}$ "Y" = Yes; "N" = No; "-" = No info; "H" = heat; "VD" = variable sowing dates; "D" = drought; "L" = lodging. 
Supplementary Table 2. Significance value of regression coefficient, deviation from regression, Shukla's stability variance, and Kang's stability statistics for wheat yield $\left(\mathrm{t} \cdot \mathrm{ha}^{-1}\right)$ of 6 genotypes tested in 3 years and 3 locations over 2 management practices; and for location BR, MP, and PB for wheat yield $\left(\mathrm{t} \cdot \mathrm{ha}^{-1}\right)$ of 10 (6 same +4 different) wheat genotypes tested for 3 years over 2 management practices.

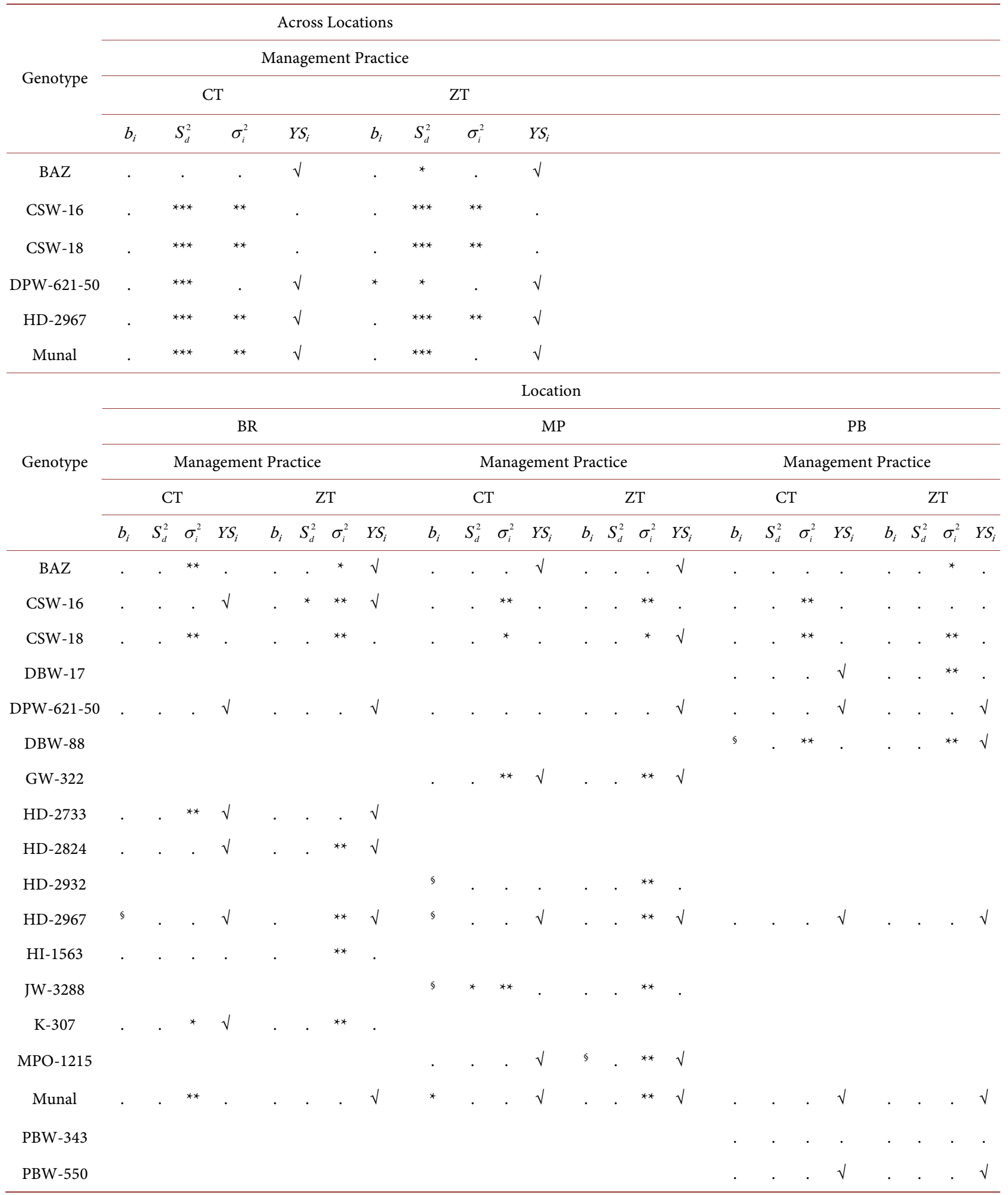

${ }^{*},{ }^{* *}$ and ${ }^{* * *}$ significantly different from unity for the regression coefficients or slope $\left(b_{i}\right)$ and from zero for the deviation from regression $\left(S_{d}^{2}\right)$ and Shukla's stability variance $\left(\sigma_{i}^{2}\right)$ at $0.05,0.01$ and 0.001 levels of probability, respectively. " $\$$ " indicates negative slope. " $\sqrt{ }$ " indicates stable according to Kang stability statistics $\left(Y S_{i}\right)$. 

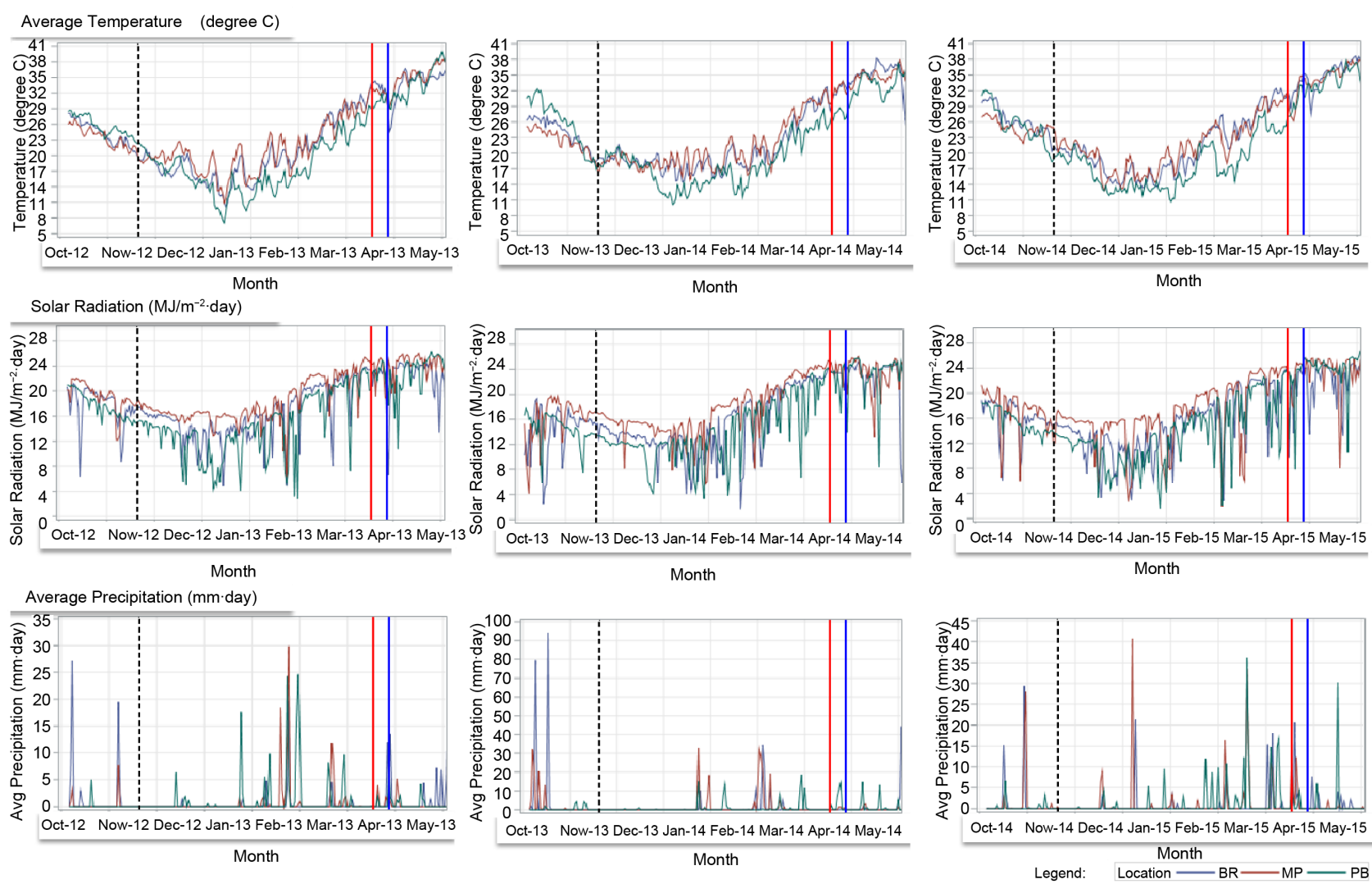

Supplementary Figure 1. Daily average temperature $\left({ }^{\circ} \mathrm{C}\right)$, Solar Radiation $\left(\mathrm{MJ} \cdot \mathrm{m}^{-2} \cdot \mathrm{day}^{-1}\right)$ and average precipitation $\left(\mathrm{mm} \cdot \mathrm{day}{ }^{-1}\right)$ for location BR, MP and PB for the year 2012 to 2015. Vertical dashed line represents date of sowing (Nov 15). Vertical solid red and blue lines represent harvest date for location BR and MP, and PB, respectively. (Source: NASA, USA). 

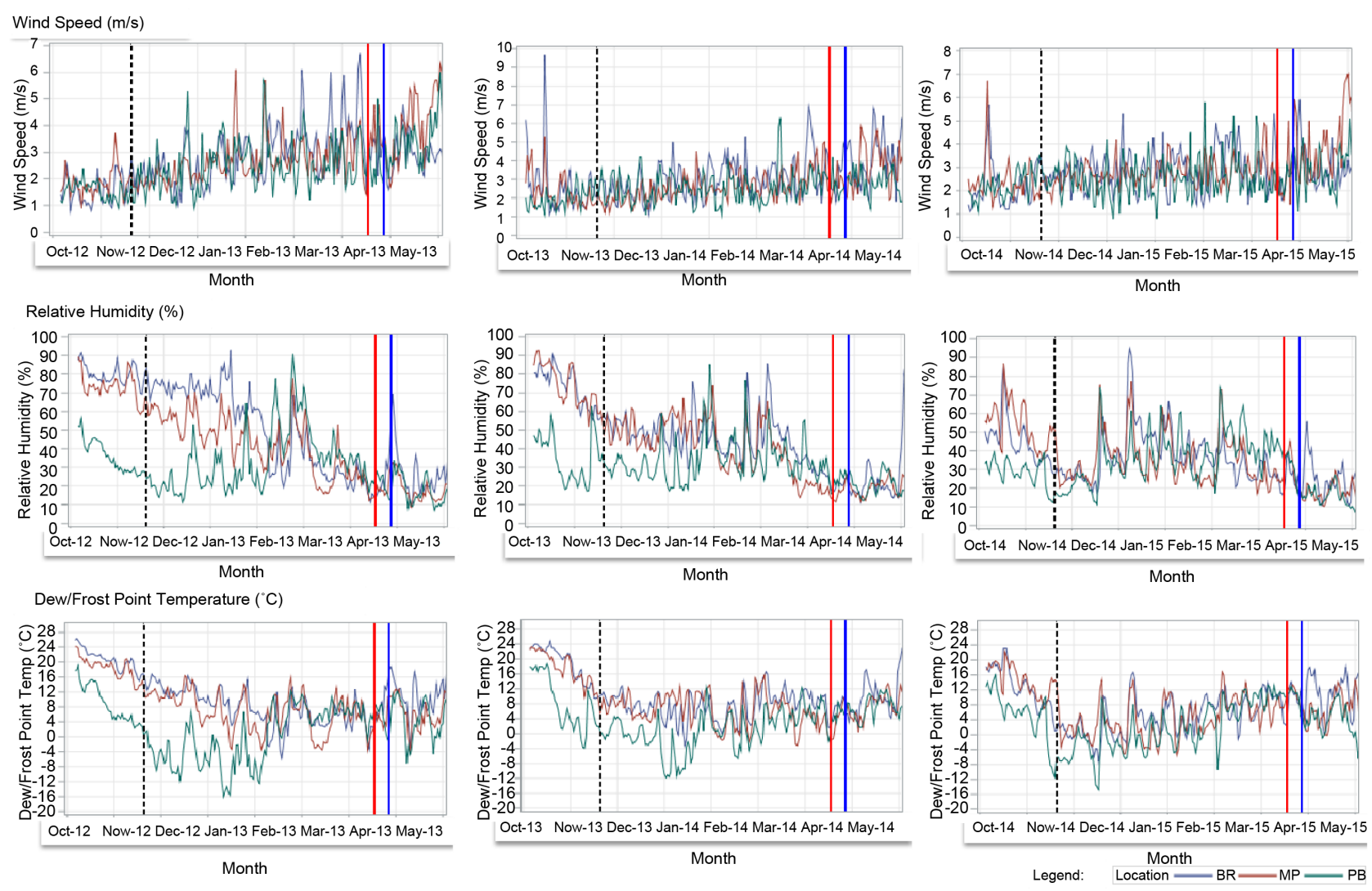

Supplementary Figure 2. Daily wind speed $\left(\mathrm{m} \cdot \mathrm{s}^{-1}\right)$, relative humidity $(\%)$ and dew/frost point temperature $\left({ }^{\circ} \mathrm{C}\right)$ for location $\mathrm{BR}$, MP and PB for the year 2012 to 2015. Vertical dashed line represents date of sowing (Nov 15). Vertical solid red and blue lines represent harvest date for location BR and MP, and PB, respectively. (Source: NASA, USA). 

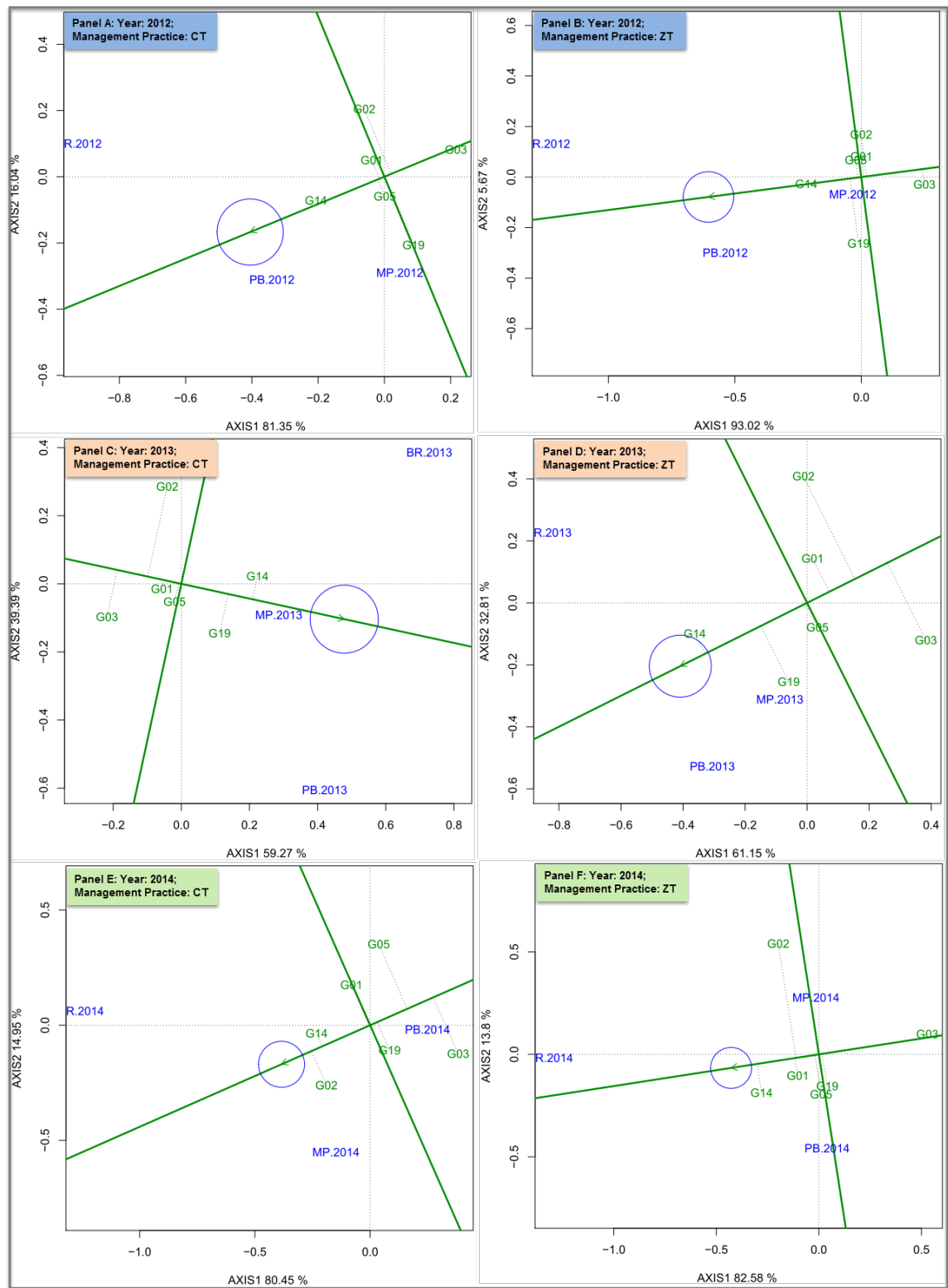

Supplemental Figure 3. The polygon (which-won-where) view of BLUP-genotype main effects plus genotype $\times$ location interaction effect (BLUP-GGL) biplot for year 2012 (Panel A and Panel B), 2013 (Panel C and Panel D) and 2014 (Panel E and Panel F) for yield of 6 genotypes tested in 3 years and 3 locations over 2 management practices. The biplots were based on Scaling $=0$, Centering $=0$, and SVP $=2$. Key to the labels of genotype and location is presented in abbreviation section. 

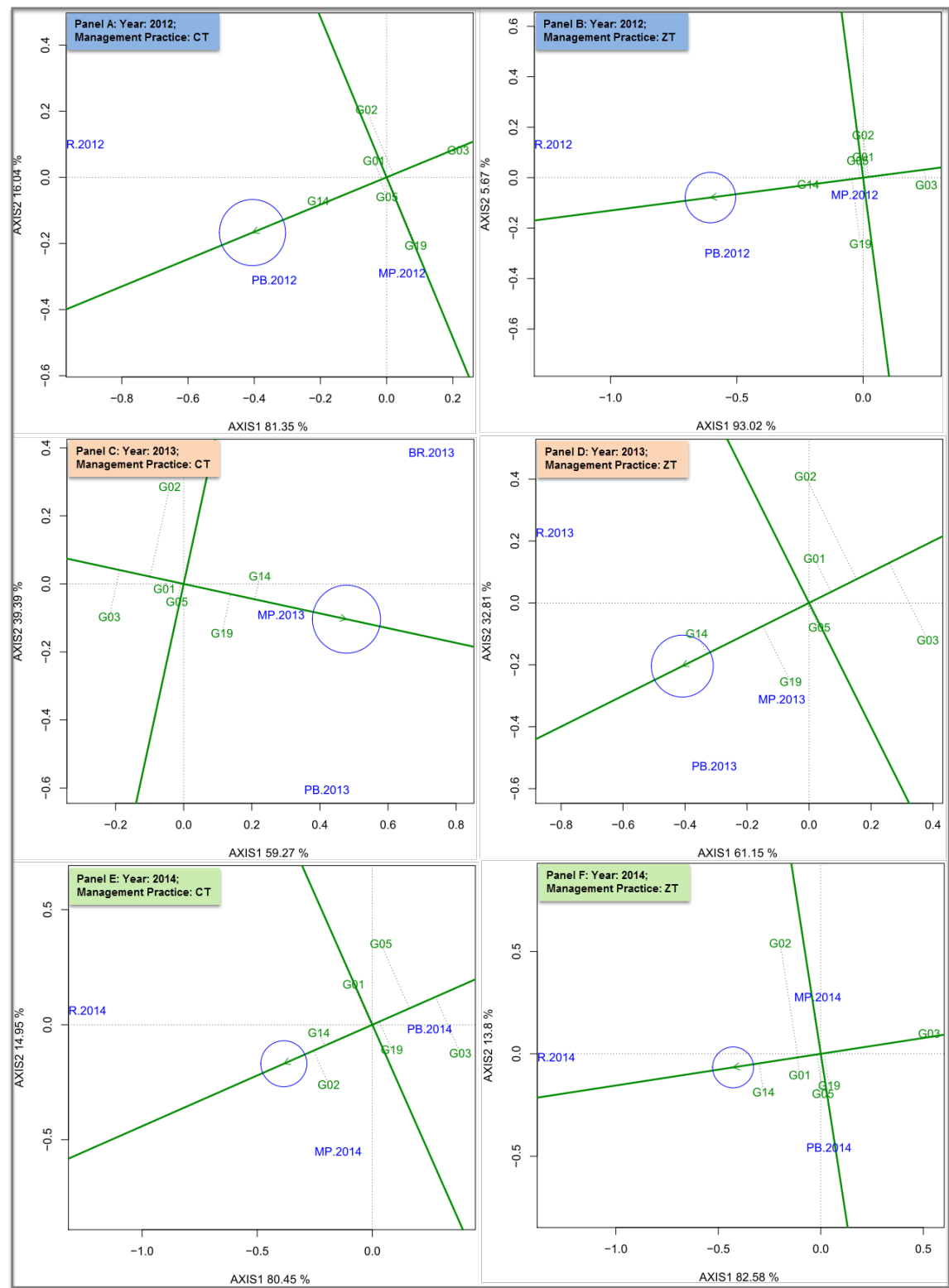

Supplemental Figure 4. The mean vs. stability view of BLUP-genotype main effects plus genotype $\mathrm{x}$ location interaction effect (BLUP-GGL) biplot for year 2012 (Panel A and Panel B), 2013 (Panel C and Panel D) and 2014 (Panel E and Panel F) for yield of 6 genotypes tested in 3 years and 3 locations over 2 management practices. The biplots were based on Scaling $=0$, Centering $=0$, and SVP $=2$. Key to the labels of genotype and location is presented in abbreviation section. 


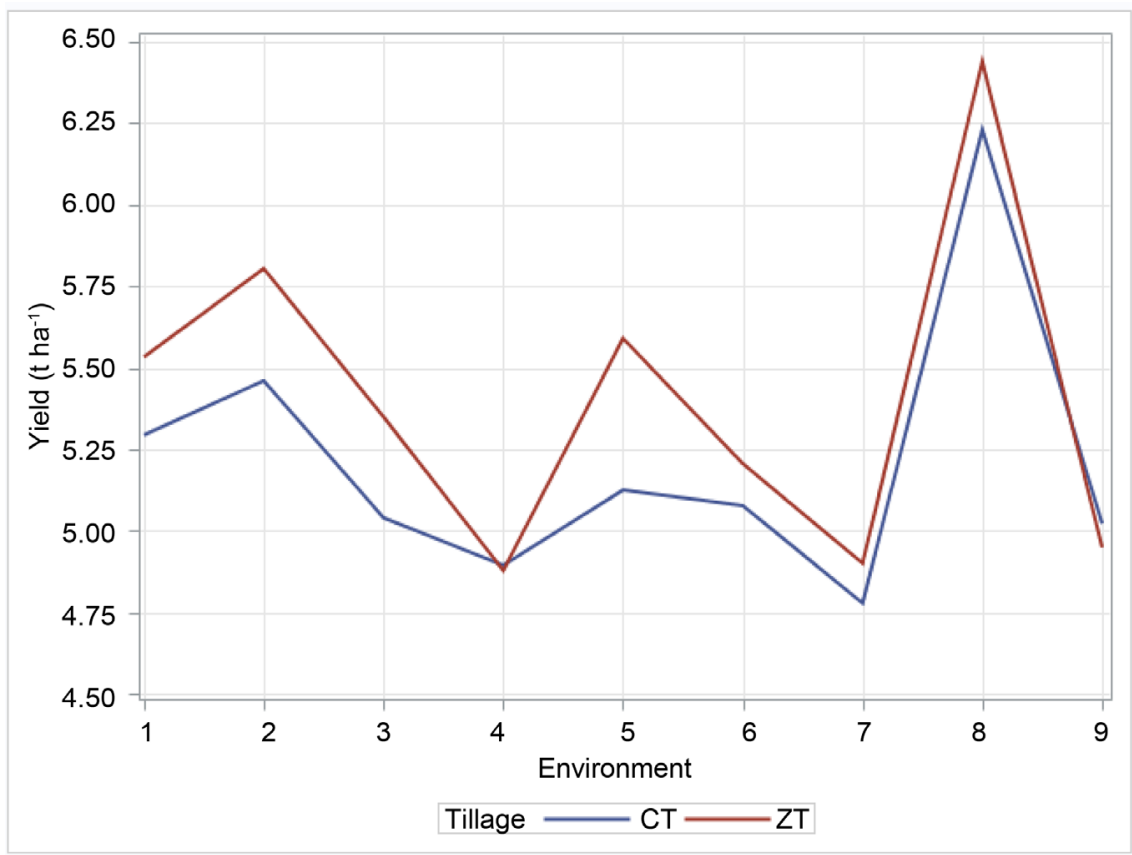

Supplemental Figure 5. Mean (95\% confidence interval) yield of 6 genotypes tested in 9 environments ( 3 locations $\times 3$ years) over 2 management practices (CT and ZT). The shaded band represents $95 \%$ confidence interval. The environment $1,2,3,4,5,6,7,8$, and 9 represent BR-2012, BR-2013, BR-2014, MP-2012, MP-2013, MP-2014, PB-2012, PB-2013, and PB-2014, respectively.

\section{Scientific Research Publishing}

Submit or recommend next manuscript to SCIRP and we will provide best service for you:

Accepting pre-submission inquiries through Email, Facebook, LinkedIn, Twitter, etc. A wide selection of journals (inclusive of 9 subjects, more than 200 journals)

Providing 24-hour high-quality service

User-friendly online submission system

Fair and swift peer-review system

Efficient typesetting and proofreading procedure

Display of the result of downloads and visits, as well as the number of cited articles

Maximum dissemination of your research work

Submit your manuscript at: http://papersubmission.scirp.org/

Or contact ajps@scirp.org 